This item was submitted to Loughborough's Research Repository by the author.

Items in Figshare are protected by copyright, with all rights reserved, unless otherwise indicated.

\title{
Performance assessment framework based on competitive priorities for sustainable freight transportation systems
}

PLEASE CITE THE PUBLISHED VERSION

https://doi.org/10.1016/j.trd.2020.102663

PUBLISHER

Elsevier

VERSION

AM (Accepted Manuscript)

\section{PUBLISHER STATEMENT}

This paper was accepted for publication in the journal Transportation Research Part D: Transport and Environment and the definitive published version is available at https://doi.org/10.1016/j.trd.2020.102663

\section{LICENCE}

CC BY-NC-ND 4.0

\section{REPOSITORY RECORD}

Pathak, Devendra, Ravi Shankar, and Alok Choudhary. 2020. "Performance Assessment Framework Based on Competitive Priorities for Sustainable Freight Transportation Systems". Loughborough University. https://hdl.handle.net/2134/13337111.v1. 


\title{
Performance Assessment Framework based on Competitive Priorities for Sustainable Freight Transportation Systems
}

\author{
Devendra Kumar Pathak ${ }^{\mathrm{a} *}$, Ravi Shankar ${ }^{\mathrm{b}}$, Alok Choudhary ${ }^{\mathrm{c}}$ \\ ${ }^{a}$ Department of Operations Management \& Decision Sciences, Indian Institute of Management Kashipur, \\ Uttarakhand, India \\ bepartment of Management Studies, Indian Institute of Technology Delhi, New Delhi, India \\ 'Department of Management Science and Operations Management, School of Business and Economics, \\ Loughborough University, Leicestershire, UK
}

\begin{abstract}
Stringent environmental norms and growing demands for energy-efficient and cost-effective freight shipping have put organizations under immense pressure to consider sustainability aspects while assessing their performance. Moreover, amid growing awareness about competitive priorities, it has become prudent to understand how an organization's sustainability performance is balanced against competitive priorities. Therefore, this study attempts to develop an integrated performance assessment framework (PAF) on the basis of competitive priorities for sustainable freight transportation (SFT) systems. A unified approach consisting of fuzzy group decision-making, fuzzy evidential reasoning approach, and expected utility concept is utilized to assess critical success factors of SFT based on four competitive priorities. The applicability of the developed model is exhibited through a case example, and sensitivity analysis is also performed to examine its robustness. This competitive performance score based PAF would facilitate logistics professionals in selecting the most competitive SFT system.
\end{abstract}

Keywords: Performance Assessment Framework; Fuzzy Evidential Reasoning Algorithm (FERA); Fuzzy Group Decision-making (FGDM); Competitive Priorities; Sustainable Freight Transportation; Sensitivity Analysis.

\section{INTRODUCTION}

An economical, energy-efficient, and reliable freight transportation (FT) system is of prime significance for fulfilling the increasing demands of the industry. Freight transportation plays a pivotal role in the development of the regional economy, shaping smart cities, generating

\footnotetext{
*Corresponding Author. Email: pathakdev15@gmail.com, Tel.: +91 8860903951
} 
employment, and substantial revenue. The transportation sector contributes to about $20 \%$ of global energy consumption (Craig et al., 2013; Ratanavaraha and Jomnonkwao, 2015) and 24\% of the global $\mathrm{CO}_{2}$ emissions ( $\mathrm{Li}$ and $\mathrm{Zhang}, 2020$ ). Amid the unprecedented growth of the freight transport sector across the globe, it is also prudent to restrain its adverse effects on the environment and society, and hence to achieve sustainability in FT (Parikh, 2012).

Sustainability focuses on achieving the goals of economic growth, social well-being, and environmental integrity, which consist of strategic and long-term decision-making (Litman, 2007; Roth and Kåberger, 2002). Moreover, performance assessment is a managerial tool that is required for enhanced decision-making (Jakhar, 2015). As several complexities are involved in the transport system, it is pragmatic to use a performance management system (PMS) to analyze the system (Gholami and Ziaee, 2017). To enhance the performance of any freight transportation system, it is inevitable first to measure its current performance. Recent studies have witnessed the growing interest of scholars for evaluating the sustainability performance of the transport sector (Bandeira et al., 2019; Kumar and Anbanandam, 2020; Rajak et al., 2016). Moreover, researchers also indicate the growing negative externalities linked to FT (Bektas et al., 2019; Demir et al., 2015). Thus, to manage the negative externalities and be competitive in the prevailing dynamic market requirements, it becomes prudent for freight operators (e.g., carriers, logistics service providers (LSPs)) to analyze their sustainability performance.

\subsection{Competitive Priorities for Freight Transport Sector}

Competitive priorities denote an organization's strategic preferences that are chosen to contend in the market (Hayes and Wheelwright, 1984; Idris and Naqshbandi, 2019). The fundamental competitive priorities for the manufacturing and service sector are cost, delivery, quality, innovation, and flexibility (Bouranta and Psomas, 2017; Dangayach and Deshmukh, 2006). These are defined as follows (Bouranta and Psomas, 2017; Kathuria et al., 1999; Phusavat and Kanchana, 2008).

Cost: "ability to distribute and produce products at low cost";

Quality: "ability to maintain high conformance to the service/product specification";

Delivery: "ability to meet the promised delivery schedules for customer orders";

Flexibility: "ability to respond to rapid changes in the service/ product or process";

Innovation: "ability to commence innovative amendments to existing services/production processes and continuously develop new ones". 
In the service sector, the focus on competitive priorities facilitates to satisfy and fulfill customers' expectations (Phusavat and Kanchana, 2008). Researchers unanimously consider innovation, cost, and flexibility as the crucial competitive priorities for the logistics service sector (Liu and Lyons, 2011; Kroes and Ghosh, 2010; Yeung et al., 2012). 'Delivery of quality services' combines the principles of quality and delivery for service processes, and thereby 'delivery of quality services' is considered as one of the most significant competitive priorities for the service industry (Idris and Naqshbandi, 2019). Therefore, this research considers 'delivery of quality services' (DQ), 'innovation' (IN), 'cost' (CO), and 'flexibility' (FL) as the key competitive priorities for the FT sector.

\subsection{Research Gap and Research Objectives}

Recent studies published in "Transportation Research Part D: Transport and Environment" bring out the growing interest of researchers towards sustainability assessment in the transport sector. For instance, Stefaniec et al. (2020) assess the sustainability performance of inland transportation in China; Wang (2019) integrates environmental and safety factors to evaluate road transport sustainability; Bandeira et al. (2019) evaluate the sustainability performance of last-mile freight distribution strategies of a postal company; Stephenson et al. (2018) pinpoint key interventions for sustainable transportation in New Zealand, and Miller et al. (2016) analyze the sustainability performance of public transport by using a composite sustainability index. Furthermore, in a recent review study on environmental sustainability for LSPs, Centobelli et al. (2017) highlight that 'assessment of sustainability performance' and 'factors affecting the implementation of environmental sustainability programs' are the two key research gaps.

Moreover, in today's hypercompetitive market place, to outperform, organizations need to emphasize on achieving sustainability as well as competitive advantage. Competitive priorities assist in adopting sustainability measures, which, in turn, enhance the competitive advantage of an organization (Govindan et al., 2016). Competitive priorities play an indispensable role in achieving sustainability targets of an organization (Phusavat and Kanchana, 2008). It is thereby evident that there is a remarkable and growing literature on sustainable transportation; however, earlier studies have not given much attention to analyze the performance of sustainable freight transportation (SFT) based on competitive priorities (Galeazzo and Klassen, 2015; Lin and Tseng, 2016). In essence, it is prudent to analyze how an organization's sustainability performance is balanced against competitive priorities. Consequently, it becomes significant to evaluate the sustainability performance of FT 
systems based on competitive priorities. Therefore, this study analyzes the critical success factors (CSFs) that affect the performance of SFT based on competitive priorities associated with service sector (i.e., DQ, IN, CO, FL) by utilizing a unified approach consisting of fuzzy group decisionmaking (FGDM), fuzzy evidential reasoning algorithm (FERA), and the concept of expected utility. Accordingly, the prime research objectives considered are delineated as follows.

- $\quad$ To assess and prioritize the CSFs of SFT on the basis of competitive priorities.

- To propose an integrated performance assessment framework based on competitive priorities to model uncertainties of the SFT system.

This is one of the very few studies that analyze the interaction between sustainability performance and competitive priorities (Galeazzo and Klassen, 2015; Laari et al., 2018). This research contributes to the existing literature by analyzing the sustainability performance of FT systems based on competitive priorities. This study also provides a comprehensive summary of the journal papers on sustainability performance assessment in the transport sector. This study proposes a competitive performance score (CPS) based performance assessment framework (PAF) for SFT systems and demonstrates its applicability through a case example. Moreover, this study exemplifies the use of an improved and efficient technique to aggregate individual fuzzy opinions of experts in the multicriteria decision making (MCDM) environment. The outcomes of this study facilitate logistics practitioners in identifying key CSFs that are crucial to improve competitive performance. The computed CPS value acts as an objective measure for evaluating the competitive performance of an SFT system.

The rest of the paper is organized as follows. Section 2 presents a comprehensive literature review on performance assessment and competitive priorities for the transport sector. An integrated approach combining FERA, FGDM, and expected utility theory, to attain the specified objectives, is discussed in Section 3. Section 4 demonstrates the applicability of the proposed framework through a case example. A sensitivity analysis is carried out in Section 5. The subsequent section explains the effect of variations in the weight of competitive priorities on the CPS value of six dimensions of SFT. Section 7 presents results and discussion. Eventually, Section 8 brings out conclusions and scope for future research. 


\section{LITERATURE REVIEW}

We review the extant literature in three parts; the first part examines the extant literature on performance assessment of sustainable transport sector, the second parts reviews the extant literature on competitive priorities for the transport sector, and the third part deals with the literature related to the interaction of competitive priorities and sustainability performance assessment.

\subsection{Review of Literature for Performance assessment of Sustainable Transportation Sector}

In a business environment, sustainability facilitates to handle economic, environmental, and social concerns in a holistic manner (Corbo and Glaus, 2019; Zhao et al., 2020). Havenga and Simpson (2018) highlight the significant contribution of freight logistics in achieving sustainability targets. The pressing need for sustainability and performance assessment is well reported among practitioners and researchers in the domain of operations management (Magon et al., 2018).

In the recent past, a few researchers have also highlighted the significance of sustainability performance assessment in the area of freight transportation (Kumar and Anbanandam, 2020; Rai et al., 2017; Stefaniec et al., 2020). For example, Kumar and Anbanandam (2020) propose an indexbased model for assessing the social and environmental sustainability performance of FT by utilizing fuzzy logic and fuzzy best-worst technique. Abbasi and Nilsson (2016) assert that sustainability in logistics operations can be achieved by performing activities that cause the maximum economic and societal gains, whereas minimizing the detrimental environmental impacts. Green transport corridors (GTCs) indicate long-distance transportation of freight traffic between major hubs that aim to decrease environmental impact and to increase safety and energy efficiency by utilizing sustainable logistics solutions, inter-modality, and advanced technologies (Blinge, 2014; Hunke and Prause, 2013). Panagakos (2016) brings out that GTCs are environmentally sustainable and economically efficient. Prause (2014) proposes a balanced scorecard approach for green corridors. Prause and Schröder (2015) pinpoint different key performance indicators (KPIs) to check and manage the performance of GTCs. Moreover, Panagakos and Psaraftis (2017) propose a freight corridor evaluation method that comprises of disintegrating the entire corridor into various shipping chains, picking a set of chains based on the outcomes of the shipping model, evaluating disintegrated chains on the basis of KPIs, and subsequently by utilizing suitable weights compute the corridor-level KPIs by combining the chain-level KPIs. Table 1 illustrates the summary of published papers that address the issue of sustainability performance in the transportation sector. 
Table 1 Summary of Papers on Sustainability Performance Assessment in the Transport Sector

\begin{tabular}{|c|c|c|c|c|c|c|c|c|c|c|}
\hline \multirow[t]{2}{*}{ S.No. } & \multirow[t]{2}{*}{ Authors } & \multirow[t]{2}{*}{$\begin{array}{l}\text { Type of study/ } \\
\text { Country }\end{array}$} & \multirow[t]{2}{*}{ Contribution } & \multirow{2}{*}{$\begin{array}{l}\text { Compet } \\
\text { itive } \\
\text { Priority }\end{array}$} & \multirow[t]{2}{*}{$\begin{array}{l}\text { Focus } \\
\text { Area }\end{array}$} & \multicolumn{3}{|c|}{$\begin{array}{l}\text { Sustainability } \\
\text { Dimension }\end{array}$} & \multirow[t]{2}{*}{$\begin{array}{l}\text { Additional } \\
\text { Dimension }\end{array}$} & \multirow[t]{2}{*}{$\begin{array}{l}\text { Methods/ } \\
\text { Tools }\end{array}$} \\
\hline & & & & & & $\mathrm{EC}$ & EN & SO & & \\
\hline 1. & $\begin{array}{l}\text { Kumar and } \\
\text { Anbanandam } \\
(2020)\end{array}$ & $\begin{array}{l}\text { Case } \quad \text { Study/ } \\
\text { India }\end{array}$ & $\begin{array}{l}\text { This study develops an index-based model for } \\
\text { analyzing the social and environmental } \\
\text { sustainability performance of FT. }\end{array}$ & - & Freight & - & $\checkmark$ & $\checkmark$ & - & $\begin{array}{l}\text { Fuzzy logic } \\
\text { and Fuzzy } \\
\text { best-worst } \\
\text { technique }\end{array}$ \\
\hline 2. & $\begin{array}{l}\text { Bandeira et al. } \\
(2019)\end{array}$ & $\begin{array}{l}\text { Review and } \\
\text { case example/ } \\
\text { Brazil }\end{array}$ & $\begin{array}{l}\text { This study proposes a model to analyze } \\
\text { different strategies for parcel distribution and } \\
\text { signifies that the electric tricycle is the best } \\
\text { alternative for the last mile postal delivery. }\end{array}$ & - & Freight & $\checkmark$ & $\checkmark$ & $\checkmark$ & - & $\begin{array}{l}\text { Equations } \\
\text { based } \\
\text { assessment } \\
\text { approach }\end{array}$ \\
\hline 3. & $\begin{array}{l}\text { Kumar and } \\
\text { Anbanandam } \\
(2019)\end{array}$ & $\begin{array}{ll}\text { Case } & \text { Study/ } \\
\text { India } & \end{array}$ & $\begin{array}{l}\text { This study develops an index-based PAF for } \\
\text { analyzing the social sustainability performance } \\
\text { of FT. }\end{array}$ & - & Freight & - & - & $\checkmark$ & - & Fuzzy logic \\
\hline 4. & $\begin{array}{l}\text { Pathak et al. } \\
(2019)\end{array}$ & $\begin{array}{ll}\text { Case } & \text { Study/ } \\
\text { India } & \end{array}$ & $\begin{array}{l}\text { This study pinpoints the CSFs of SFT by } \\
\text { performing a Delphi study. This research } \\
\text { employs total interpretive structure modeling } \\
\text { (TISM) to establish inter-relationship among } \\
\text { the identified CSFs. It utilizes the Fuzzy } \\
\text { Analytical Hierarchy Process (FAHP) to } \\
\text { prioritize these CSFs. }\end{array}$ & - & Freight & $\checkmark$ & $\checkmark$ & $\checkmark$ & $\begin{array}{l}\text { Safety, } \\
\text { advanced } \\
\text { technology, } \\
\text { efficiency }\end{array}$ & $\begin{array}{l}\text { Delphi study, } \\
\text { TISM, FAHP }\end{array}$ \\
\hline 5. & $\begin{array}{l}\text { Solomon et al. } \\
(2019)\end{array}$ & $\begin{array}{l}\text { Empirical } \\
\text { study/ } \\
\text { Southeast } \\
\text { Europe } \\
\text { countries }\end{array}$ & $\begin{array}{l}\text { This study utilizes the concept of institutional } \\
\text { theory and signifies that the implementation of } \\
\text { resilient and green FT practices positively } \\
\text { affects social performance. }\end{array}$ & - & Freight & $\checkmark$ & $\checkmark$ & $\checkmark$ & - & $\begin{array}{l}\text { Structural } \\
\text { equation } \\
\text { modeling } \\
\text { (SEM) }\end{array}$ \\
\hline 6. & $\begin{array}{l}\text { Bandeira et al. } \\
(2018)\end{array}$ & $\begin{array}{ll}\text { Case } & \text { study/ } \\
\text { Brazil } & \end{array}$ & $\begin{array}{l}\text { This study evaluates the sustainability } \\
\text { performance of urban freight transport (UFT) } \\
\text { from the perspective of freight operators. This } \\
\text { research develops a composite index based } \\
\text { framework to choose the best delivery } \\
\text { alternative. }\end{array}$ & - & Freight & $\checkmark$ & $\checkmark$ & $\checkmark$ & - & Fuzzy logic \\
\hline 7. & Li et al. (2018) & $\begin{array}{ll}\text { Case } & \text { study/ } \\
\text { China } & \end{array}$ & $\begin{array}{l}\text { This research develops a framework to analyze } \\
\text { the environmental performance of } 21 \text { freight } \\
\text { transport seaports. }\end{array}$ & - & Freight & - & $\checkmark$ & - & - & $\begin{array}{l}\text { Data } \\
\text { envelopment } \\
\text { analysis } \\
\text { (DEA) }\end{array}$ \\
\hline 8. & $\begin{array}{l}\text { Ellram and } \\
\text { Murfield (2017) }\end{array}$ & Review & $\begin{array}{l}\text { This study systematically analyzes the extant } \\
\text { literature on environmental sustainability in FT } \\
\text { and also reports future research directions. }\end{array}$ & - & Freight & - & $\checkmark$ & - & - & \\
\hline
\end{tabular}




\begin{tabular}{|c|c|c|c|c|c|c|c|c|c|c|}
\hline 9. & He et al. (2017) & $\begin{array}{l}\text { Review and } \\
\text { multiple-case } \\
\text { study/ China }\end{array}$ & $\begin{array}{l}\text { This study proposes a performance } \\
\text { measurement system for analyzing low-carbon } \\
\text { logistics. }\end{array}$ & - & Freight & $\checkmark$ & $\checkmark$ & $\checkmark$ & - & \\
\hline 10. & Rai et al. (2017) & $\begin{array}{l}\text { Case study/ } \\
\text { Belgium }\end{array}$ & $\begin{array}{l}\text { This study proposes a policy assessment } \\
\text { framework for UFT. }\end{array}$ & - & Freight & $\checkmark$ & $\checkmark$ & $\checkmark$ & - & $\begin{array}{l}\text { Multi-actor } \\
\text { multi-criteria } \\
\text { analysis }\end{array}$ \\
\hline 11. & $\begin{array}{l}\text { Rajak et al. } \\
(2016)\end{array}$ & $\begin{array}{l}\text { Case example/ } \\
\text { India }\end{array}$ & $\begin{array}{l}\text { This paper develops a sustainability } \\
\text { performance assessment framework for urban } \\
\text { transportation systems. }\end{array}$ & - & $\begin{array}{l}\text { Freight as } \\
\text { well as } \\
\text { Passenger }\end{array}$ & $\checkmark$ & $\checkmark$ & $\checkmark$ & $\begin{array}{l}\text { Transport } \\
\text { system } \\
\text { effectiveness }\end{array}$ & Fuzzy logic \\
\hline 12. & $\begin{array}{l}\text { Khorheh et al. } \\
(2015)\end{array}$ & $\begin{array}{l}\text { Review and } \\
\text { Empirical/ } \\
\text { Australia }\end{array}$ & $\begin{array}{l}\text { This study performs a socio-environmental } \\
\text { performance analysis of transportation } \\
\text { systems. }\end{array}$ & - & Freight & - & $\checkmark$ & $\checkmark$ & - & SEM \\
\hline 13. & $\begin{array}{l}\text { Shiau et al. } \\
(2015)\end{array}$ & $\begin{array}{l}\text { Case example / } \\
\text { Taiwan }\end{array}$ & $\begin{array}{l}\text { This paper proposes a hierarchical indicator } \\
\text { structure to assess transport sustainability and } \\
\text { unveils that transport sustainability in the } \\
\text { energy aspect is almost stable. }\end{array}$ & - & $\begin{array}{l}\text { Freight as } \\
\text { well as } \\
\text { Passenger }\end{array}$ & $\checkmark$ & $\checkmark$ & $\checkmark$ & Energy & $\begin{array}{l}\text { Principal } \\
\text { component } \\
\text { analysis }\end{array}$ \\
\hline 14. & $\begin{array}{l}\text { Jeon et al. } \\
(2013)\end{array}$ & $\begin{array}{l}\text { Case study/ } \\
\text { USA }\end{array}$ & $\begin{array}{l}\text { This study signifies the role of sustainability } \\
\text { performance evaluation in transportation } \\
\text { planning. }\end{array}$ & - & $\begin{array}{l}\text { Freight as } \\
\text { well as } \\
\text { Passenger }\end{array}$ & $\checkmark$ & $\checkmark$ & $\checkmark$ & $\begin{array}{l}\text { Transport } \\
\text { system } \\
\text { effectiveness }\end{array}$ & $\begin{array}{l}\text { Composite } \\
\text { sustainability } \\
\text { index (CSI) } \\
\text { tool }\end{array}$ \\
\hline 15. & $\begin{array}{l}\text { Shiau and } \\
\text { Chuang (2012) }\end{array}$ & $\begin{array}{l}\text { Case example / } \\
\text { Taiwan }\end{array}$ & $\begin{array}{l}\text { This study reveals that gravel transportation } \\
\text { can be more sustainable by shifting loads from } \\
\text { trucks to intermodal transport. }\end{array}$ & - & Freight & $\checkmark$ & $\checkmark$ & $\checkmark$ & - & $\begin{array}{l}\text { AHP, SEE } \\
\text { (social-eco- } \\
\text { efficient) } \\
\text { Approach }\end{array}$ \\
\hline 16. & $\begin{array}{l}\text { Awasthi and } \\
\text { Chauhan (2011) }\end{array}$ & $\begin{array}{l}\text { Numerical } \\
\text { Example/ } \\
\text { Canada }\end{array}$ & $\begin{array}{l}\text { This study utilizes a transport sustainability } \\
\text { index-based framework to assess different } \\
\text { sustainable city transport solutions. }\end{array}$ & - & $\begin{array}{l}\text { Freight as } \\
\text { well as } \\
\text { Passenger }\end{array}$ & $\checkmark$ & $\checkmark$ & $\checkmark$ & $\begin{array}{l}\text { Energy, } \\
\text { Transport }\end{array}$ & $\begin{array}{l}\text { AHP, } \\
\text { Dempster- } \\
\text { Shafer theory }\end{array}$ \\
\hline 17. & $\begin{array}{l}\text { Ramani et al. } \\
(2011)\end{array}$ & $\begin{array}{ll}\text { Case } & \text { study/ } \\
\text { USA }\end{array}$ & $\begin{array}{l}\text { This paper develops a PAF to assess and } \\
\text { improve the sustainability performance of a } \\
\text { sustainable transportation agency. }\end{array}$ & - & Freight & $\checkmark$ & $\checkmark$ & $\checkmark$ & - & $\begin{array}{l}\text { Delphi } \\
\text { Analysis, } \\
\text { MCDM }\end{array}$ \\
\hline 18. & $\begin{array}{l}\text { Jeon et al. } \\
(2010)\end{array}$ & $\begin{array}{l}\text { Case study/ } \\
\text { USA }\end{array}$ & $\begin{array}{l}\text { This paper analyzes the sustainability } \\
\text { performance for different transportation (and } \\
\text { land use) scenarios. }\end{array}$ & - & $\begin{array}{l}\text { Freight as } \\
\text { well as } \\
\text { Passenger }\end{array}$ & $\checkmark$ & $\checkmark$ & $\checkmark$ & $\begin{array}{l}\text { Transport } \\
\text { system } \\
\text { effectiveness }\end{array}$ & $\begin{array}{l}\text { MCDM, CSI, } \\
\text { weighted sum } \\
\text { model }\end{array}$ \\
\hline 19. & Litman (2007) & $\begin{array}{l}\text { Review and } \\
\text { Field study }\end{array}$ & $\begin{array}{l}\text { This study facilitates to pinpoint indicators for } \\
\text { sustainable and livable transportation planning. }\end{array}$ & - & $\begin{array}{l}\text { Freight as } \\
\text { well as } \\
\text { Passenger }\end{array}$ & $\checkmark$ & $\checkmark$ & $\checkmark$ & - & \\
\hline
\end{tabular}




\begin{tabular}{|c|c|c|c|c|c|c|c|c|c|}
\hline 20. & $\begin{array}{l}\text { Jeon and } \\
\text { Amekudzi } \\
(2005)\end{array}$ & Review & $\begin{array}{l}\text { This study analyzes } 16 \text { sustainable } \\
\text { transportation initiatives to define transport } \\
\text { sustainability and how to evaluate it. }\end{array}$ & - & $\begin{array}{l}\text { Freight as } \\
\text { well as } \\
\text { Passenger }\end{array}$ & $\checkmark$ & $\checkmark$ & $\checkmark$ & $\begin{array}{l}\text { Transport } \\
\text { system } \\
\text { effectiveness }\end{array}$ \\
\hline 21. & $\begin{array}{l}\text { Richardson } \\
(2005)\end{array}$ & Review/ USA & $\begin{array}{l}\text { This study delineates analysis frameworks to } \\
\text { represent interaction among indicators of } \\
\text { transport sustainability. }\end{array}$ & - & $\begin{array}{l}\text { Freight as } \\
\text { well as } \\
\text { Passenger }\end{array}$ & $\checkmark$ & $\checkmark$ & $\checkmark$ & - \\
\hline
\end{tabular}

It is worth mentioning that the research by Pathak et al. (2019) is a good starting point to work on SFT, but their study requires substantial advancements to analyze the interaction between sustainability performance of FT systems and competitive priorities. Therefore, this research primarily extends the study of Pathak et al. (2019) by evaluating the identified CSFs of SFT on the basis of competitive priorities of the service sector. This study highlights the four key competitive priorities of the transport sector (delivery of quality services' (DQ), 'innovation' (IN), ‘cost' (CO), and 'flexibility' (FL)). Pathak et al. (2019) developed a sustainability performance index (SPI)-based performance assessment framework (PAF) for assessing the performance of SFT systems. However, this study takes an extra step to identify key CSFs that are crucial to improve competitive performance and proposes a competitive performance score (CPS) based PAF for SFT systems by utilizing a unified approach consisting of fuzzy group decision-making (FGDM), fuzzy evidential reasoning algorithm (FERA), and the concept of expected utility. In this study, the integrated methodologies employed (i.e., FGDM and FERA) can easily handle uncertainties associated with the decision-making procedure due to subjective judgments and incomplete information. 


\subsection{Review of Literature on Competitive Priorities for the Transport Sector}

In today's dynamic and hypercompetitive business environment, an organization's success is highly dependent on the correctness with which it opts the competitive priorities (Prajogo and Mcdermott, 2011). The growing competition requires an organization to focus on improving its internal operations and integrating its suppliers in the entire supply chain activities to build competitive capabilities (i.e., cost, flexibility, delivery, and quality) (Olhager and Prajogo, 2012). The research on competitive priorities in the domain of the logistics sector is still in its nascent stage. Logistics professionals should emphasize on competitive priorities of the service industry (i.e., DQ, IN, CO, FL) (Bouranta and Psomas, 2017; Idris and Naqshbandi, 2019) when trying to attain their sustainability goals.

Kroes and Ghosh (2010) highlight cost, quality, flexibility, innovation, and time priority as significant competitive priorities while evaluating the effect of congruence on supply chain performance. For a third-party LSP, Liu and Lyons (2011) signify that the earlier studies unanimously present that the combination of cost, quality, flexibility, delivery, and innovation may be used to represent operational performance. In the present dynamic market scenario, competitive priorities lead a firm to implement sustainability-related measures for attaining a higher competitive advantage (Govindan et al., 2016), which in turn will yield enhanced organizational performance (Li et al., 2006). Despite the indispensable role of competitive priorities in performance improvement, the existing literature significantly lacks to demonstrate any study on performance assessment and competitive priorities in the domain of SFT (as also evident from Table 1).

\subsection{Review of Literature for the Interaction of Competitive Priorities and Sustainability Performance Assessment}

Galeazzo and Klassen (2015) signify that sustainability is linked to competitive priorities. By incorporating sustainability concepts in a supply chain, an organization may effectively respond to the burgeoning stakeholder pressure and enhance revenue and competitiveness (Ansari and Kant, 2017). Despite the increasing interest in analyzing the interaction between competitive priorities and sustainability, merely a few researchers have attempted to study this interaction. For instance, Laari et al. (2018) propose a path analysis model to analyze the competitive priorities and green supply chain management (GSCM) practices of logistics service providers (LSPs) and investigate their association with financial and environmental performance. The findings reveal that GSCM practices do not affect financial performance but significantly affect environmental performance. Nonetheless, this paper has 
overlooked the social sustainability aspect during the analysis. Galeazzo and Klassen (2015) report that manufacturing strategies consist of sustainability as well as the traditional competitive priorities. The authors also examine the relationships among manufacturing strategies, the organizational context, and the adoption of social and environmental practices. The outcomes of this study signify that sustainability is linked to the two dimensions of competitive priorities (i.e., quality and delivery).

In the recent past, sustainability performance assessment in the transport sector has gained proliferating research attention across the globe. The research on competitive priorities in the domain of the transport sector is also evolving at a faster pace. Nowadays, LSPs have started to focus on improving their sustainability performance. However, the biggest challenge before LSPs is to identify which sustainability factors would lead to attaining higher competitive advantage. Despite these growing interests, only a few researchers (Galeazzo and Klassen, 2015; Laari et al., 2018) have attempted to work on the interaction of competitive priorities and sustainability performance. As also evident from Table 1, earlier studies significantly lack to analyze the sustainability performance of FT based on competitive priorities. Consequently, this issue remains one of the significant research gaps in the extant literature. This research is an attempt to address this existing gap in the literature by analyzing the sustainability performance of FT based on competitive priorities.

\section{AN INTEGRATED APPROACH TO ANALYZE THE CSFS OF SFT}

Performance assessment in the field of SFT requires quantitative as well as qualitative assessment. Qualitative assessment is primarily based on the experts' subjective judgment and thus may have uncertainties involved in the decision-making. Therefore, this research employs a fuzzy evidential reasoning algorithm (FERA) to analyze the performance of SFT systems. FERA can handle multicriteria decision making (MCDM) problems for subjective attributes and the combination of both quantitative and qualitative attributes (Ayati et al., 2012). A unified approach by using FGDM, FERA,

and expected utility concept is utilized to assess and prioritize the CSFs of SFT based on competitive priorities. A step by step procedure is explained as follows.

\subsection{Research Flow Diagram}

The proposed framework for this study to attain the identified objectives is demonstrated, as shown in Figure 1. 


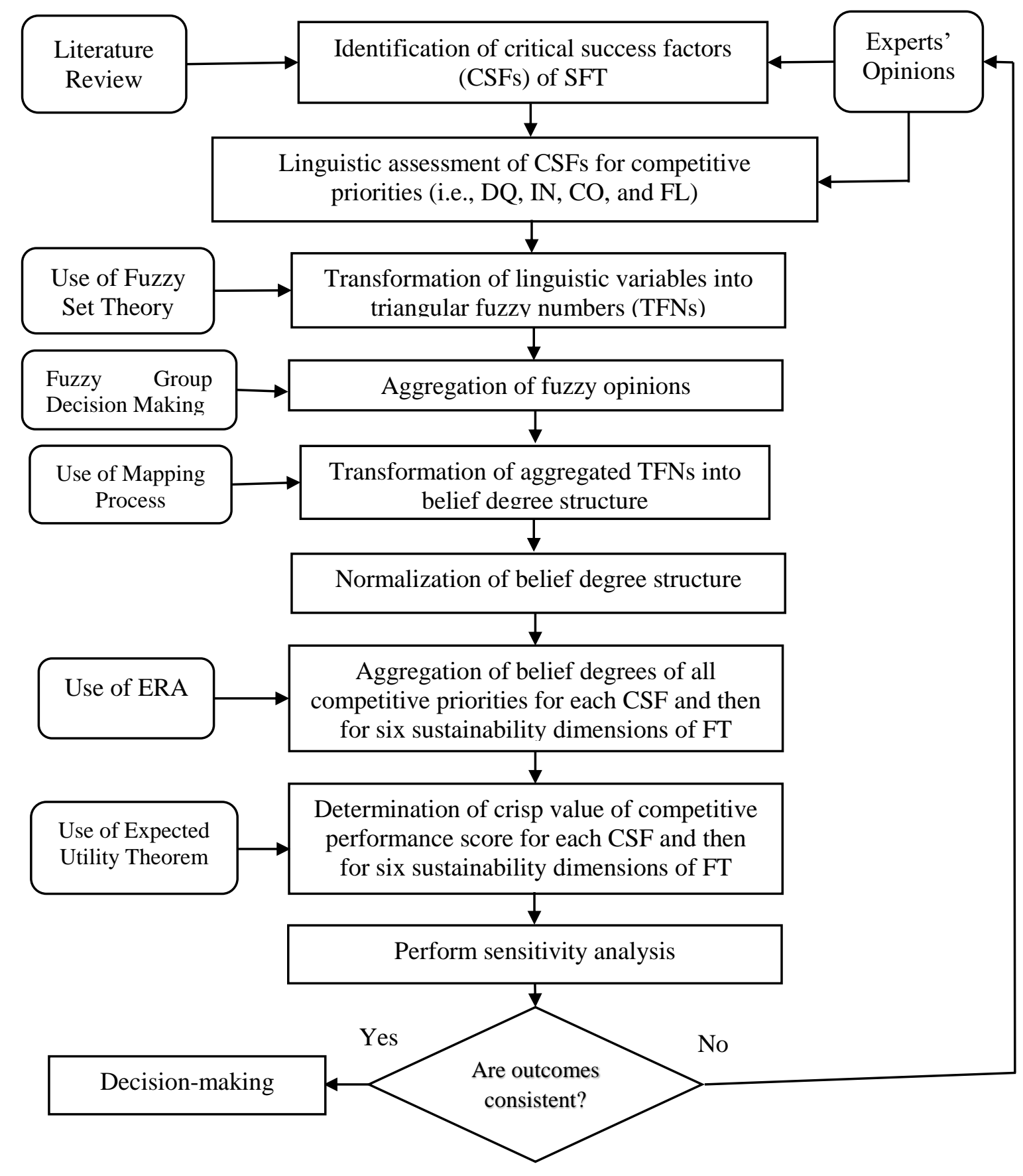

Figure 1 Proposed Research Framework

\subsection{Identification of CSFs of SFT}

The CSFs can be termed as the key elements that are essential for any business organization to attain the specified goals and ensure its success (Rockart, 1979). By reviewing the extant literature and performing a Delphi study, Pathak et al. (2019) identify 34 CSFs that affect the sustainability performance of FT and classify these CSFs into six dimensions of sustainability. Pathak et al. (2019) 
develop a sustainability performance index (SPI)-based framework for assessing the performance of SFT systems. The authors bring out the importance of three emergent dimensions (i.e., efficiency $(\mathrm{EF})$, employing advanced technology (EM), and safety $(\mathrm{SA}))$ along with the triple bottom line aspects of sustainability (i.e., social, economic, and environmental) in assessing the performance of SFT systems.

In this study, we consider 34 CSFs of SFT, as identified by Pathak et al. (2019). These CSFs are categorized into six dimensions of sustainability and significantly affect the sustainability performance of FT systems. For further information on these CSFs, interested readers may refer to Pathak et al. (2019). A list of the considered CSFs is depicted in Table 2. 
Table 2. A Finalized list of CSFs influencing performance of SFT

\begin{tabular}{|c|c|c|c|}
\hline Factors of SFT & Code & CSFs of SFT & References \\
\hline \multirow{6}{*}{$\begin{array}{l}\text { Economic } \\
\text { Factor }(\mathbf{E C})\end{array}$} & EC-1 & Operating cost & Bandeira et al. (2018); Castillo and Pitfield (2010) \\
\hline & $\mathrm{EC}-2$ & Personnel training & Kumar and Anbanandam (2019); Pathak et al. (2019) \\
\hline & $\mathrm{EC}-3$ & Loading Factor & Bandeira et al. (2018); Piecyk and Mckinnon (2010); Liljestrand (2016); \\
\hline & EC-4 & Return on Investment (ROI) & Pathak et al. (2019) \\
\hline & EC-5 & Economic growth & Castillo and Pitfield (2010); Jeon and Amekudzi (2005) \\
\hline & EN-1 & Air Pollution & Bandeira et al. (2018); Jeon et al. (2013); Reisi et al. (2014) \\
\hline \multirow{6}{*}{$\begin{array}{l}\text { Environmental } \\
\text { Factor }(\mathrm{EN})\end{array}$} & EN-2 & Noise Level & Bandeira et al. (2018); Kumar and Anbanandam (2020); Litman (2007) \\
\hline & EN-3 & Vibration Level & Khorheh et al. (2015) \\
\hline & EN-4 & Climate Change & Litman (2007); Rajak et al. (2016) \\
\hline & EN-5 & Conventional Fossil Fuel consumption & Litman (2007); Rajak et al. (2016) \\
\hline & EN-6 & Visual Intrusion & Demir et al. (2015); Taniguchi et al. (2014) \\
\hline & EN-7 & $\begin{array}{l}\text { Complying with Government Regulations for } \\
\text { Green Practices Implementation }\end{array}$ & Pathak et al. (2019) \\
\hline \multirow{6}{*}{$\begin{array}{l}\text { Efficiency } \\
\text { Factor (EF) }\end{array}$} & $\mathrm{EF}-1$ & Energy Efficiency & He et al. (2017); Shiau et al. (2015) \\
\hline & $\mathrm{EF}-2$ & Quality Management & Awasthi and Chauhan (2011); Bandeira et al. (2018) \\
\hline & $\mathrm{EF}-3$ & Drivers' Efficiency & ERTRAC (2011); Leonardi and Baumgartner (2004) \\
\hline & $\mathrm{EF}-4$ & Efficient Transport Operations & Rajak et al. (2016) \\
\hline & $\mathrm{EF}-5$ & On-time Delivery & Lai et al. (2002) \\
\hline & EF-6 & Distribution Planning & Awasthi and Chauhan (2012); Crainic and Laporte (1997) \\
\hline \multirow{7}{*}{$\begin{array}{l}\text { Employing } \\
\text { Advanced } \\
\text { Technology } \\
\text { Factor (EM } \\
\text { ) }\end{array}$} & EM-1 & Electronic $\quad$ Data Interchange (EDI) & Perego et al. (2011); Yoshimoto and Nemoto (2005) \\
\hline & EM-2 & Radio Frequency & ERTRAC (2011); Yoshimoto and Nemoto (2005) \\
\hline & & Identification (RFID) & \\
\hline & EM-3 & Global Positioning & Taniguchi et al. (2014); Yoshimoto and Nemoto (2005) \\
\hline & & System (GPS) & \\
\hline & EM-4 & Intelligent Transportation System (ITS) & ERTRAC (2011); Yoshimoto and Nemoto (2005) \\
\hline & EM-5 & Top Management Support for ICT Usage & ERTRAC (2011); Mondragon et al. (2017); Tob-Ogu et al. (2018) \\
\hline \multirow{5}{*}{$\begin{array}{l}\text { Safety } \\
\text { (SA) }\end{array}$} & SA-1 & Accident Rate & Santos and Ribeiro (2013); Shiau et al. (2015) \\
\hline & $\mathrm{SA}-2$ & Injury Severity Level & Bandeira et al. (2018); Shiau et al. (2015) \\
\hline & $\mathrm{SA}-3$ & Cargo Security & Awasthi and Chauhan (2011); He et al. (2017) \\
\hline & $\mathrm{SA}-4$ & Customer Satisfaction & Awasthi and Chauhan (2012); Reisi et al. (2014); Santos and Ribeiro (2013) \\
\hline & SA-5 & Adoption of Safety Standards & Pathak et al. (2019) \\
\hline \multirow{6}{*}{$\begin{array}{l}\text { Social } \\
\text { (SO) }\end{array}$} & SO-1 & Traffic Clogging & Bandeira et al. (2018); Janjevic et al. (2019); Kumar and Anbanandam (2019) \\
\hline & $\mathrm{SO}-2$ & Equity & Jeon et al. (2010); Santos and Ribeiro (2013) \\
\hline & $\mathrm{SO}-3$ & Health Risk & Kumar and Anbanandam (2019); Litman (2007); Santos and Ribeiro (2013) \\
\hline & $\mathrm{SO}-4$ & Quality of Life & Behrends (2011); Jeon et al. (2010) \\
\hline & SO-5 & $\begin{array}{l}\text { Awareness towards } \\
\text { Programs }\end{array}$ & Jeon and Amekudzi (2005) \\
\hline & SO-6 & Drivers' Healthcare & ERTRAC (2011) \\
\hline
\end{tabular}




\subsection{Assessment of CSFs using Fuzzy Set Theory}

After identifying the CSFs of SFT, the next step is to assess these CSFs on the basis of selected criteria. The literature on competitive priorities of the service sector forms the basis for the performance criteria considered in this study. Therefore, we consider four criteria (i.e., competitive priorities) to evaluate the competitive performance of all CSFs and sustainability dimensions of FT systems. All CSFs of SFT are qualitative in nature with an emphasis on assessing sustainability performance based on competitive priorities. As experts' expertise would be required in decision-making for performance evaluation, it is recommended to use linguistic variables (Wan et al., 2019). For linguistic assessment of CSFs, a fivepoint scale (very low, low, medium, high, and very high) is used to facilitate experts for analyzing CSFs on the basis of different competitive priorities. Afterward, the concepts of fuzzy set theory (FST) (Zadeh, 1965) are used to transform linguistic evaluations into triangular fuzzy numbers (TFNs) (please refer to Table 3) (John et al., 2014).

Table 3 Conversion of Linguistic Variables to TFN

\begin{tabular}{|l|l|}
\hline Level of significance & Membership Function \\
\hline Very Low $[\mathrm{VL}]$ & {$[0.00,0.00,0.25]$} \\
\hline Low $[\mathrm{L}]$ & {$[0.00,0.25,0.50]$} \\
\hline Medium $[\mathrm{M}]$ & {$[0.25,0.50,0.75]$} \\
\hline High $[\mathrm{H}]$ & {$[0.50,0.75,1.00]$} \\
\hline Very High $[\mathrm{VH}]$ & {$[0.75,1.00,1.00]$} \\
\hline
\end{tabular}

The significance level for CSFs of SFT to achieve competitive performance can be defined by using TFNs (as depicted in Table 4). A TFN is represented with the help of parameters $a, b$, and $c$. Further, a centroid value (C) can be utilized to compare the significance level of different CSFs of SFT. The centroid value (C) is calculated by using Equation (1) (John et al., 2014).

$C=\frac{1}{3}(a+b+c)$ 
Table 4 Details of the Linguistic Scale used for Performance Assessment of SFT

\begin{tabular}{|l|l|l|l|l|}
\hline $\begin{array}{l}\text { Linguistic scale for } \\
\text { performance analysis of } \\
\text { CSFs of SFT on the basis } \\
\text { of competitive priorities }\end{array}$ & $\begin{array}{l}\text { Description of } \\
\text { assessment } \\
\text { TFN }\end{array}$ & $\begin{array}{l}\text { Centroid } \\
\text { value (C) }\end{array}$ & $\begin{array}{l}\text { Range } \\
\text { competitive } \\
\text { performance score }\end{array}$ & $\begin{array}{l}\text { Significance } \\
\text { level of CSF }\end{array}$ \\
\hline Very Low (VL) & $(0.00,0.00,0.25)$ & 0.083 & $0-0.24$ & $\begin{array}{l}\text { Not significant } \\
\text { at all }\end{array}$ \\
\hline Low (L) & $(0.00,0.25,0.50)$ & 0.25 & $0.25-0.49$ & $\begin{array}{l}\text { Slightly } \\
\text { significant }\end{array}$ \\
\hline Medium (M) & $(0.25,0.50,0.75)$ & 0.5 & $0.5-0.74$ & $\begin{array}{l}\text { Moderately } \\
\text { significant }\end{array}$ \\
\hline High (H) & $(0.50,0.75,1.00)$ & 0.75 & $0.75-0.91$ & Significant \\
\hline Very High (VH) & $(0.75,1.00,1.00)$ & 0.92 & $0.92-1.00$ & $\begin{array}{l}\text { Extremely } \\
\text { significant }\end{array}$ \\
\hline
\end{tabular}

\subsection{Methodology}

This study utilizes a unified approach consisting of FGDM, FERA, and expected utility theory to assess the CSFs of SFT on the basis of competitive priorities. These methodologies are briefly explained as follows.

\subsubsection{Aggregation of Fuzzy Opinions}

In an MCDM problem, as an expert's opinion for a particular criterion may encompass fuzziness, ambiguity, and subjectivity for the given alternative, FST offers an effective means to handle these uncertainties involved in the human judgments (Chen, 1998). When several experts participate in a decision-making problem, it becomes essential to combine individual fuzzy opinions of experts for attaining a collective opinion (Hsu and Chen, 1996). Chen (1998) proposes an improved and efficient method for aggregation of fuzzy opinions in the MCDM environment. The author reports several advantages of the proposed method over the similarity aggregation method for aggregation of fuzzy opinions, as presented by Hsu and Chen (1996).

Suppose that each expert $E_{d}(d=1,2, \ldots, D)$ uses a non-negative TFN $\widetilde{R}_{d}=\left(a_{d}, b_{d}, c_{d}\right)$ to depict the subjective estimate of the rating to a given criterion and alternative, where $0 \leq a_{d} \leq b_{d} \leq c_{d} \leq 1$. Further, the degree of significance of an expert $E_{d}$ is assumed as $w_{d}$, where $w_{d} \in[0,1]$ and $\sum_{d=1}^{D} w_{d}=$ 1. The five-step algorithm is explained as follows (Chen, 1998). 
1: Estimate the degree of agreement $S\left(\tilde{R}_{d}, \tilde{R}_{q}\right)$ of the collected views for each pair of experts $E_{d}$ and $E_{q}$, where $S\left(\tilde{R}_{d}, \tilde{R}_{q}\right) \in[0,1], 1 \leq d \leq D, 1 \leq q \leq D$, and $d \neq q$.

Let $\tilde{X}$ and $\tilde{Y}$ be two standardized TFNs, $\tilde{X}=\left(a_{1}, b_{1}, c_{1}\right), \tilde{Y}=\left(a_{2}, b_{2}, c_{2}\right)$. The degree of agreement between $\tilde{X}$ and $\tilde{Y}$ is estimated as follows.

$S(\tilde{X}, \tilde{Y})=1-\frac{\left|a_{1}-a_{2}\right|+\left|b_{1}-b_{2}\right|+\left|c_{1}-c_{2}\right|}{3}$

2: For expert $E_{d}$, compute the average degree of agreement $D A\left(E_{d}\right)$ as follows.

$D A\left(E_{d}\right)=\frac{1}{D-1} \sum_{d=1 d \neq q}^{D} S\left(\tilde{R}_{d}, \tilde{R}_{q}\right)$

3: For expert $E_{d}$, estimate the relative degree of agreement $R D A\left(E_{d}\right)$ as follows.

$R D A\left(E_{d}\right)=\frac{D A\left(E_{d}\right)}{\sum_{d=1}^{D} D A\left(E_{d}\right)}$

4: If the weight of the degrees of significance and the relative degree of agreement for experts are $z_{1}$ and $z_{2}$, respectively, consensus degree coefficient $C\left(E_{d}\right)$ for expert $E_{d}$ is computed as follows.

$C\left(E_{d}\right)=\left(\frac{z_{1}}{z_{1}+z_{2}} \times w_{d}\right)+\left(\frac{z_{2}}{z_{1}+z_{2}} \times R D A\left(E_{d}\right)\right)$

Where $z_{1} \in[0,1]$ and $z_{2} \in[0,1]$.

Further, as highlighted by Hsu and Chen (1996), when there is no consideration for the degree of significance of experts (i.e., $\alpha=0$ )

$C\left(E_{d}\right)=R D A\left(E_{d}\right)$

Where, $\alpha=\frac{z_{1}}{z_{1}+z_{2}}$ and $1-\alpha=\frac{z_{2}}{z_{1}+z_{2}}$

5: The aggregated fuzzy opinion $\tilde{R}$ is calculated as follows.

$\tilde{R}=C\left(E_{1}\right) \otimes R_{1} \oplus C\left(E_{2}\right) \otimes R_{2} \oplus \ldots \oplus C\left(E_{D}\right) \otimes R_{D}$

Where, operators $\bigoplus$ and $\otimes$ denote fuzzy addition and multiplication operator, respectively. 


\subsubsection{Transformation of TFNs into Belief Degree Structure}

A belief degree can be defined as the degree of expectation that, for a particular criterion, will provide an expected result to the given alternative (John et al., 2014). Aggregated TFN value is transformed into a belief degree structure by employing the concepts presented by earlier studies (Godaliyadde et al., 2010; John et al., 2014). Afterward, the normalized belief degree values for each CSF are calculated, as discussed in Section 4.2.

\subsubsection{Evidential Reasoning Algorithm (ERA) and the Concept of Expected Utility}

An ERA is proposed to analyze quantitative as well as qualitative attributes involved in multiple attribute decision-making problems (Wan et al., 2018; Yang, 2001; Zhou et al., 2019). ERA combines the concept of the Dempster-Shaffer (D-S) theory of evidence and a distributed modeling assessment framework (Wan et al., 2019; Qin et al., 2020). This distributed modeling framework facilitates to assess each attribute by utilizing a set of mutually exclusive assessment grades. Moreover, probabilistic uncertainty is addressed by a belief degree structure and fuzzy uncertainty by considering fuzzy linguistic assessment in the ERA. ERA can effectively handle different kinds of uncertainties (e.g., ignorance, fuzziness, and incomplete information) (Wan et al., 2019; Zhou et al., 2019).

Unlike most conventional MCDM techniques, ERA utilizes a belief degree structure to illustrate the estimation of an attribute as a distribution. Moreover, instead of aggregating average scores, ERA applies aggregation concepts of D-S theory to combine belief degrees (Akhoundi and Nazif, 2018; Wan et al., 2018). ERA facilitates combining multilevel criteria in a hierarchical framework, and it is easily implemented by using intelligent decision system (IDS) software (Yan et al., 2015). A rational means to express fuzziness is to use linguistic variables in place of numerical assessment. Thereby, for ease of decision-making process, FST offers a systematic approach to consider linguistic variables (Lai, 2008).

The FST can be combined with ERA to deal with pragmatic cases, where fuzziness and ignorance in data are prevailing (Yang et al., 2006). The FERA (i.e., the combination of FST and ERA) is extensively used by researchers in analyzing decision-making problems (Cao et al., 2019; John et al., 2014; Yang et al., 2009). This study utilizes FERA to analyze the performance of SFT systems. FERA is utilized as it is able to handle uncertainties involved in the decision analysis. To analyze the performance of SFT based on competitive priorities, a three-step ERA method, as proposed by Akhoundi and Nazif (2018), is utilized and explained as follows. 
Assume performance assessment of SFT as an MCDM problem with $\mathrm{M}$ alternatives (i.e., CSFs) $o_{l}(l=1, \ldots, M)$, one overall goal and $L$ basic criteria (i.e., competitive priorities) $f_{i}(i=1, \ldots, L)$. Suppose $F$ as a set of $L$ basic criteria:

$F=\left\{f_{i}, i=1, \ldots, L\right\}$

Assume this set comprises of all competitive priorities affecting the evaluation of the overall goal.

Suppose the relative weights of these $L$ criteria are given by $\theta=\left\{\theta_{i}, i=1, \ldots, L\right\}$ and can be normalized as follows.

$0 \leq \theta_{i} \leq 1, \sum_{i=1}^{L} \theta_{i}=1$

Assume $\mathrm{N}$ distinct assessment grades are described by a comprehensive set as denoted by $G_{n}(n=1, \ldots, N)$, where $G_{n}$ is the $\mathrm{n}^{\text {th }}$ assessment grade and it is considered that $G_{n+1}$ is preferred to $G_{n}$.

$G=\left\{G_{n}, n=1, \ldots, N\right\}$

An MCDM problem with $o_{l}(l=1, \ldots, M)$ alternatives and $f_{i}(i=1, \ldots, L)$ criteria is mathematically depicted as follows.

$S\left(f_{i}\left(o_{l}\right)\right)=\left\{\left(G_{n}, \beta_{n, i}\left(o_{l}\right)\right), n=1, \ldots, N\right\}, \quad i=1, \ldots, L, \quad l=1, \ldots, M$

Where, $\beta_{n, i}\left(o_{l}\right) \geq 0$ and $\sum_{n=1}^{N} \beta_{n, i}\left(o_{l}\right) \leq 1$. $\beta_{n, i}\left(o_{l}\right)$ indicates a belief degree. The evaluation outcomes of each alternative (i.e., CSF) on each competitive priority are denoted as follows.

$D_{g}=\left(S\left(f_{i}\left(o_{l}\right)\right)\right)_{L \times M}$

Note that a criterion may have its own set of evaluation grades that can be dissimilar from the other criteria.

\section{Step 2: Attribute aggregation by using the ER algorithm}

In this study, we consider four competitive priorities (i.e., DQ, IN, CO, FL) as an exhaustive set of criteria for analyzing the performance of SFT systems. The recursive ER algorithm is employed to assess the decision alternatives $o_{l}(l=1, \ldots, M)$ by aggregating $\mathrm{L}$ criteria. The assessments depicted in Equation (11) - (12) for an alternative $o_{l}$ may be aggregated as follows. 


$$
f_{i}(i=1, \ldots, L)
$$

The belief degree is converted into basic probability masses as follows:

Let $p_{n, i}$ is a basic probability mass that represents the amount for $\mathrm{i}^{\text {th }}$ basic attribute $e_{i}$ which is evaluated to $\mathrm{n}^{\text {th }}$ grade $G_{n} \cdot p_{n, i}$ and $p_{H, i}$ are determined as follows

$p_{n, i}=\theta_{i} \beta_{n, i}\left(o_{l}\right), \quad n=1, \ldots, N ; i=1, \ldots, L$

Let $p_{H, i}$ is the residual probability mass unallocated to any individual grade. In the modified ER algorithm (Yang and $\mathrm{Xu}, 2002$ ), this residual probability mass is decomposed into two parts: 1) $\bar{p}_{H, i}$ and 2) $\tilde{p}_{H, i}$, where

$\bar{p}_{H, i}=1-\theta_{i}$ and $\tilde{p}_{H, i}=\theta_{i}\left(1-\sum_{n=1}^{N} \beta_{n, i}\right)$

With $p_{H, i}=\bar{p}_{H, i}+\tilde{p}_{H, i}$

$\bar{p}_{H, i}$ is the first part of the residual probability mass unallocated to an individual assessment grade that indicates the degree to which other attributes can play a role in the assessment. And, $\tilde{p}_{H, i}$ is another part of the residual probability mass unallocated to an individual assessment grade that exists due to the incompleteness in the assessment $S\left(f_{i}\right)$.

Let $p_{n, I(i)}(n=1,2, \ldots, N), \tilde{p}_{H, I(i)}$, and $\bar{p}_{H, I(i)}$ represent the combined probability masses produced by combining the first $i$ assessments. The aggregation process with two decomposed masses to compute the combined probability masses (i.e., $p_{n, I(i+1)}, \tilde{p}_{H, I(i+1)}$, and $\left.\bar{p}_{H, I(i+1)}\right)$ for the first $(i+1)$ assessments is recursively performed as follows (Yang and $\mathrm{Xu}, 2002$ ).

$\left\{G_{n}\right\}: p_{n, I(i+1)}=N F_{I(i+1)}\left[p_{n, I(i)} p_{n, i+1}+p_{n, i+1}\left(\bar{p}_{H, i}+\tilde{p}_{H, i}\right)+p_{n, I(i)}\left(\bar{p}_{H, i+1}+\tilde{p}_{H, i+1}\right)\right], n=1, \ldots, N$

$\{\mathrm{G}\}: \tilde{p}_{H, I(i+1)}=N F_{I(i+1)}\left[\tilde{p}_{H, I(i)} \tilde{p}_{H, i+1}+\tilde{p}_{H, I(i)} \bar{p}_{H, i+1}+\bar{p}_{H, I(i)} \tilde{p}_{H, i+1}\right]$

$\{\mathrm{G}\}: \bar{p}_{H, I(i+1)}=N F_{I(i+1)}\left[\bar{p}_{H, I(i)} \bar{p}_{H, i+1}\right]$

$N F_{I(i+1)}=\left[1-\sum_{t=1}^{N} \sum_{j=1 j \neq t}^{N} p_{t, I(i)} p_{j, i+1}\right]^{-1}, i=1, \ldots, L-1$

where, $N F_{I(i+1)}$ is a normalizing factor in facilitating $\sum_{n=1}^{N} p_{n, I(i+1)}+p_{H, I(i+1)}=1$.

Note that $p_{n, I(1)}=p_{n, 1}(n=1,2, \ldots, N), \tilde{p}_{H, I(1)}=\tilde{p}_{H, 1}, \bar{p}_{H, I(1)}=\bar{p}_{H, 1}$, and $p_{H, I(1)}=p_{H, 1}$. 
After aggregation of all L assessments, the combined belief degree is computed as follows (Yang and $\mathrm{Xu}, 2002)$.

$\left\{G_{n}\right\}: \beta_{n}=\frac{p_{n, I(L)}}{1-\bar{p}_{H, I(L)}}, \quad n=1, \ldots, N$

$\{G\}: \beta_{H}=\frac{\tilde{p}_{H, I(L)}}{1-\bar{p}_{H, I(L)}}$

In the ERA method, $\beta_{n}$ is the combined belief degree and $\beta_{H}$ is the belief degree unallocated to any individual assessment grade. $\beta_{H}$ denotes the amount of incompleteness in the assessment. It is mentioned that $\sum_{n=1}^{N} \beta_{n}\left(o_{l}\right)+\beta_{H}\left(o_{l}\right)=1$ (Yang, 2001).

The aggregated assessment for $\left(o_{l}\right)$ can be represented as follows.

$S\left(y\left(o_{l}\right)\right)=\left\{\left(G_{n}, \beta_{n}\left(o_{l}\right)\right), n=1, \ldots, N\right\}$.

Step 3: Utility estimation in the ERA method using the Expected Utility Theory

The theory of expected utility is used to obtain numerical values corresponding to the distributed estimation for each alternative on the basis of overall competitive performance score (John et al., 2014; Yang, 2001). If the utility of an assessment grade $G_{n}$ is $u\left(G_{n}\right)$, the expected utility of the aggregated assessment $S\left(y\left(o_{l}\right)\right)$ can be denoted by:

$u\left(S\left(y\left(o_{l}\right)\right)\right)=\sum_{n=1}^{N} \beta_{n}\left(o_{l}\right) u\left(G_{n}\right)$

Where $u\left(G_{n}\right)$ depicts the utility value of each linguistic variable. If decision-makers' preference data is unavailable, it is supposed that the utilities of the assessment grades are evenly distributed, so that (Yang, 2001):

$u\left(G_{n}\right)=\left(V_{n}-1\right) /\left(V_{N}-1\right)(n=1, \ldots, N)$

where $V_{n}$ denotes the ranking value of the linguistic variable under consideration $\left(G_{n}\right)$ and $V_{N}$ is the ranking value of the most preferred linguistic variable $\left(G_{N}\right)$.

The belief degree $\beta_{n}\left(o_{l}\right)$ denotes the lower bound of the possibility that $o_{l}$ is evaluated to $G_{n}$, while the upper bound of the possibility is denoted by $\left(\beta_{n}\left(o_{l}\right)+\beta_{H}\left(o_{l}\right)\right.$ ) (Akhoundi and Nazif, 2018; Yang, 2001) that forms a utility interval for an incomplete evaluation. Assume, the least favored grade $G_{1}$ has 
the minimum utility and the most favored grade $G_{N}$ has the maximum utility. So the maximum, average, and minimum utilities of $o_{l}$ are defined as follows:

$u_{\max }\left(o_{l}\right)=\sum_{n=1}^{N-1} \beta_{n}\left(o_{l}\right) u\left(G_{n}\right)+\left(\beta_{N}\left(o_{l}\right)+\beta_{H}\left(o_{l}\right)\right) u\left(G_{N}\right)$

$u_{\min }\left(o_{l}\right)=\sum_{n=2}^{N} \beta_{n}\left(o_{l}\right) u\left(G_{n}\right)+\left(\beta_{1}\left(o_{l}\right)+\beta_{H}\left(o_{l}\right)\right) u\left(G_{1}\right)$

$u_{\text {avg }}\left(o_{l}\right)=\frac{u_{\min }\left(o_{l}\right)+u_{\max }\left(o_{l}\right)}{2}$

If all the assessments $S\left(e_{i}\left(o_{l}\right)\right)$ in the generalized decision matrix are complete, $\beta_{H}\left(o_{l}\right)=0$ and $u\left(S\left(y\left(o_{l}\right)\right)\right)=u_{\max }\left(o_{l}\right)=u_{\min }\left(o_{l}\right)=u_{\text {avg }}\left(o_{l}\right)$.

\subsubsection{Sensitivity Analysis}

Sensitivity analysis aims to examine the robustness of the proposed framework. In this paper, sensitivity analysis is performed to check how a slight change in the model input data affect the model output (Yang et al., 2009). The changes in the input data may be attained by varying the model parameters or belief degrees allocated to the linguistic terms (John et al., 2014; Wan et al., 2019). To validate the robustness and rational decision-making of the methodology, the proposed performance assessment model should satisfy the following three axioms of sensitivity analysis (Wan et al., 2019; Yang et al., 2009).

Axiom 1. "A slight decrement/increment in the belief degrees related to any linguistic variables of the lowest-level criteria (i.e., competitive priorities) will cause decrement/increment in the model output (i.e., CPS value of CSFs)".

Axiom 2: "If the belief degrees related to the most preferred linguistic term of the lowest level criterion are reduced by $a$ and $b$ (i.e., simultaneously, the belief degrees related to its least preferred linguistic term are increased by $a$ and $b$ (where $1>b>a)$ ), the computed utility value for the model's output (i.e., $U_{a}$ and $U_{b}$, respectively) will be of the order $U_{a}>U_{b}$."

Axiom 3. "If $x$ and $y$ (where $y \in x$ ) criteria from all the lowest level criteria are considered, and the belief degrees related to the most preferred linguistic term of these $\mathrm{x}$ and $\mathrm{y}$ criteria are reduced by the same amount (i.e., simultaneously, the belief degrees pertaining to the least preferred linguistic term of these $\mathrm{x}$ and $\mathrm{y}$ criteria are increased by the equal amount), the computed utility value for the model's output (i.e., $U_{x}$ and $U_{y}$, respectively) will be of the order $U_{y}>U_{x}$." 


\section{APPLICABILITY OF THE PROPOSED FRAMEWORK: AN EXAMPLE OF FREIGHT TRANSPORT SECTOR}

This section explains in what way the developed framework may be utilized to evaluate sustainability CSFs based on competitive priorities for the smooth functioning of freight operators (i.e., LSPs, carriers) in the hypercompetitive market place. The applicability of the proposed model is demonstrated through an example of the freight transportation sector in India. The transport sector accounts for a 5\% share in the gross domestic product of India (Statistics Times, 2019). In India, the freight transportation sector is significantly fragmented and unorganized, and the value of this sector is estimated to be about USD 307.70 billion by 2020 (Novonous Report, 2015). In India, the transport sector contributes to around $13 \%$ of $\mathrm{CO}_{2}$ emissions, and it is the third most $\mathrm{CO}_{2}$ emitting sector. Road transportation contributes to about $93 \%$ of total transit linked $\mathrm{CO}_{2}$ emissions (IEA, 2018). In India, the freight transport sector is evolving and requires significant changes to achieve sustainability in the prevailing competitive business environment. Seven experts, associated with the transport and logistics companies in India, were interviewed for getting their opinions in linguistic terms to assess the CSFs of SFT based on competitive priorities. These experts were selected due to their expertise in the domain of sustainable logistics operations. They had the required knowledge and skills to be the key informants for this study. Each expert had a minimum experience of 14 years. Earlier studies signify that a sample size of 3-5 experts is adequate to conduct studies based on FERA (Ayati et al., 2012; John et al., 2014; Wan et al., 2019).

\subsection{Aggregation of Fuzzy Opinions}

The experts' views in the form of linguistic variables have been captured and then transformed into an equivalent TFN by using the scale as proposed by (John et al., 2014). In this study, we adopt a procedure, described by Chen (1998), to aggregate the fuzzy opinions of each expert to form a group consensus in an MCDM problem. Aggregated TFN value is computed by using Equations (2) - (7). Table 5 depicts the aggregation of experts' fuzzy opinion for CSFs (under economic dimensions) when assessed on the basis of DQ.

Table 4 Aggregation of Fuzzy Opinion for CSFs (under EC) on the Basis of DQ

\begin{tabular}{|l|l|l|l|l|l|l|l|l|l|}
\hline $\begin{array}{l}\text { S. } \\
\text { No }\end{array}$ & CSF & Expert-1 & Expert-2 & Expert-3 & Expert-4 & Expert-5 & Expert-6 & Expert-7 & Aggregated \\
\hline $\mathbf{1}$ & EC-1 & $(0.5,0.75$, & $(0.5,0.75$, & $(0.5$, & $(0.25$, & $(0.25,0.5$, & $(0.5,0.75$, & $(0.5,0.75$, & $(0.436,0.686$, \\
& & $1)$ & $0.75,1)$ & $0.5,0.75)$ & $0.75)$ & $1)$ & $1)$ & $0.936)$ \\
\hline
\end{tabular}




\begin{tabular}{|l|l|l|l|l|l|l|l|l|l|l|}
\hline $\mathbf{2}$ & $\mathbf{E C - 2}$ & $(0.75$, & $(0.75$, & $(0.5$, & $(0.75$, & $(0.5,0.75$, & $(0.75$, & $(0.5$, & 0.75, & $(0.645,0.895$, \\
& & $0.75,1)$ & $0.75,1)$ & $0.75,1)$ & $0.75,1)$ & $1)$ & $0.75,1)$ & $1)$ & $1)$ \\
\hline $\mathbf{3}$ & $\mathbf{E C - 3}$ & $(0,0.25$, & $(0,0.25$, & $(0,0.25$, & $(0.25$, & $(0.25,0.5$, & $(0.5,0.75$, & $(0.25$, & 0.5, & $(0.170,0.420$, \\
& & $0.5)$ & $0.5)$ & $0.5)$ & $0.5,0.75)$ & $0.75)$ & $1)$ & $0.75)$ & $0.670)$ \\
\hline $\mathbf{4}$ & $\mathbf{E C - 4}$ & $(0.5,0.75$, & $(0.5,0.75$, & $(0.5$, & $(0.5$, & $(0.75,0.75$, & $(0.5,0.75$, & $(0.75,0.75$, & $(0.567,0.817$, \\
& & $1)$ & $1)$ & $0.75,1)$ & $0.75,1)$ & $1)$ & $1)$ & $1)$ & $1)$ \\
\hline $\mathbf{5}$ & $\mathbf{E C - 5}$ & $(0.5,0.75$, & $(0.5,0.75$, & $(0.75$, & $(0.5$, & $(0.5,0.75$, & $(0.5,0.75$, & $(0.5$, & 0.75, & $(0.531,0.781$, \\
& & $1)$ & $1)$ & $0.75,1)$ & $0.75,1)$ & $1)$ & $1)$ & $1)$ & $1)$ \\
\hline
\end{tabular}

Similarly, the aggregation is performed for the rest of the three competitive priorities (i.e., innovation, cost, and flexibility) and other CSFs.

\subsection{Transformation of Aggregated TFNs into Belief Degree Structure}

Further, aggregated TFN value for all CSFs is transformed into belief degree structure, and then a normalized belief degree has been calculated. When assessed on the basis of DQ, the transformation of TFN for the CSF 'EC-1' is demonstrated using Figure 2. The normalized belief degree values for each CSF can be calculated by using the following procedure, as proposed by John et al. (2014).

- First of all, a uniformly distributed graph is developed to show the fuzzy membership function of TFN for the adapted five-point scale.

- The aggregated $\mathrm{TFN}_{(\mathrm{EC}-1 / \mathrm{DQ})}$ is mapped over the uniformly distributed graph for five assessment grades (VL, L, M, H, and VH). The triangle developed by plotting $\mathrm{TFN}_{(\mathrm{EC}-1 / \mathrm{DQ})}$ is shown by green lines in Figure 2.

- This green triangle (representing $\mathrm{TFN}_{(\mathrm{EC}-1 / \mathrm{DQ})}$ ) intersects with the four assessment grade triangles (i.e., L, M, H, and VH) on the uniformly distributed graph. These four intersection points are identified in Figure 2. The equivalent values for these intersecting points are determined by drawing the straight black lines, as shown in Figure 2.

- These intersecting point values represent the belief degree of $\mathrm{TFN}_{(\mathrm{EC}-1 / \mathrm{DQ})}$ for the respective assessment grades. The belief degree values for $\left.\mathrm{TFN}_{(\mathrm{EC}-1 / \mathrm{DQ})}\right)$ can be determined from Figure 2 and are depicted in Table 6.

- If the green triangle $\left(\mathrm{TFN}_{(\mathrm{EC}-1 / \mathrm{DQ})}\right)$ intersects any of the assessment grade triangles at more than one place, the highest value corresponding to the intersecting position is considered.

- In last, the belief degree values are normalized to get normalized belief degree. 
Table 6 A Sample Calculation for Transformation of $\mathrm{TFN}_{(\mathrm{EC}-1 / \mathrm{DQ})}$ into Normalized Belief Degree

\begin{tabular}{|c|c|c|c|c|c|}
\hline $\mathrm{TFN}_{(\mathrm{EC}-1 / \mathrm{DQ})}$ & \multicolumn{5}{|c|}{$(0.436,0.686,0.936)$} \\
\hline Grade & VL & $\mathrm{L}$ & M & $\mathrm{H}$ & VH \\
\hline Belief Degree & 0.000 & 0.125 & 0.630 & 0.875 & 0.375 \\
\hline Normalized Belief degree & 0.000 & 0.062 & 0.314 & 0.436 & 0.187 \\
\hline
\end{tabular}

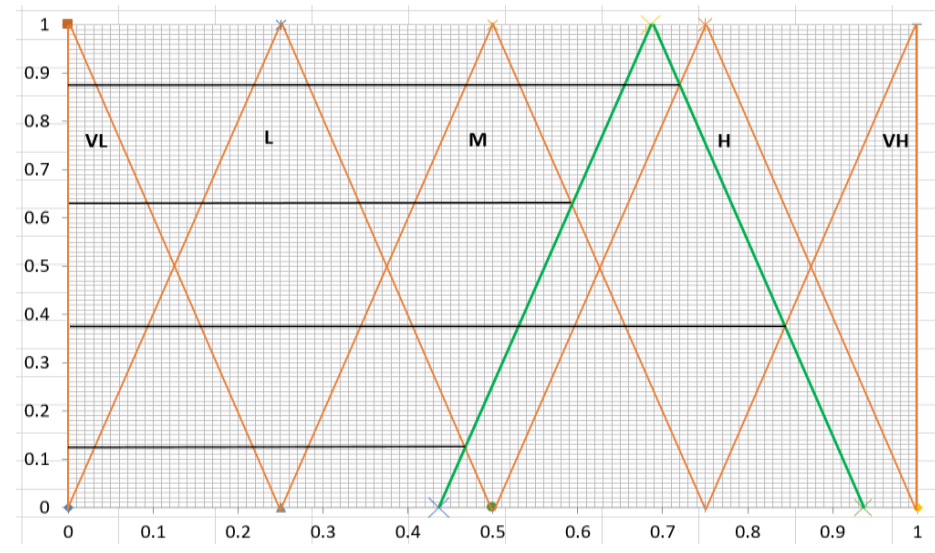

Figure 2 TFNEC-1/DQ Transformation into Belief Degree

Similarly, mapped belief degrees for all CSFs have been calculated, and then normalized belief degrees for all CSFs have been determined. Table 7 represents normalized belief degrees of all CSFs when assessed on the basis of four competitive priorities. 
Table 7 Normalized Belief Degrees of All CSF

\begin{tabular}{|c|c|c|c|c|c|c|c|c|c|c|c|c|c|c|c|c|c|c|c|c|}
\hline & \multicolumn{5}{|c|}{ DQ } & \multicolumn{5}{|c|}{ IN } & \multicolumn{5}{|c|}{$\mathrm{CO}$} & \multicolumn{5}{|c|}{ FL } \\
\hline & VL & $\mathbf{L}$ & $\mathbf{M}$ & $\mathbf{H}$ & VH & VL & $\mathbf{L}$ & $\mathbf{M}$ & $\mathbf{H}$ & VH & VL & $\mathbf{L}$ & M & $\mathbf{H}$ & VH & VL & $\mathbf{L}$ & $\mathbf{M}$ & $\mathbf{H}$ & VH \\
\hline EC-1 & 0.000 & 0.062 & 0.314 & 0.436 & 0.187 & 0.000 & 0.000 & 0.228 & 0.490 & 0.283 & 0.000 & 0.000 & 0.040 & 0.368 & 0.591 & 0.000 & 0.000 & 0.201 & 0.477 & 0.322 \\
\hline EC-2 & 0.000 & 0.000 & 0.128 & 0.433 & 0.439 & 0.000 & 0.000 & 0.166 & 0.458 & 0.376 & 0.000 & 0.000 & 0.082 & 0.400 & 0.518 & 0.000 & 0.000 & 0.166 & 0.458 & 0.376 \\
\hline EC-3 & 0.081 & 0.331 & 0.418 & 0.170 & 0.000 & 0.147 & 0.398 & 0.353 & 0.102 & 0.000 & 0.000 & 0.000 & 0.228 & 0.490 & 0.283 & 0.000 & 0.220 & 0.470 & 0.278 & 0.032 \\
\hline EC-4 & 0.000 & 0.000 & 0.201 & 0.477 & 0.322 & 0.000 & 0.062 & 0.314 & 0.436 & 0.187 & 0.000 & 0.027 & 0.277 & 0.471 & 0.225 & 0.000 & 0.186 & 0.434 & 0.314 & 0.066 \\
\hline EC-5 & 0.000 & 0.000 & 0.228 & 0.490 & 0.283 & 0.000 & 0.000 & 0.228 & 0.490 & 0.283 & 0.000 & 0.027 & 0.277 & 0.471 & 0.225 & 0.000 & 0.144 & 0.394 & 0.355 & 0.107 \\
\hline EN-1 & 0.280 & 0.493 & 0.228 & 0.000 & 0.000 & 0.000 & 0.062 & 0.314 & 0.436 & 0.187 & 0.223 & 0.471 & 0.278 & 0.027 & 0.000 & 0.280 & 0.493 & 0.228 & 0.000 & 0.000 \\
\hline EN-2 & 0.372 & 0.460 & 0.168 & 0.000 & 0.000 & 0.000 & 0.144 & 0.394 & 0.355 & 0.107 & 0.280 & 0.493 & 0.228 & 0.000 & 0.000 & 0.319 & 0.478 & 0.203 & 0.000 & 0.000 \\
\hline EN-3 & 0.147 & 0.398 & 0.353 & 0.102 & 0.000 & 0.000 & 0.186 & 0.434 & 0.314 & 0.066 & 0.280 & 0.493 & 0.228 & 0.000 & 0.000 & 0.280 & 0.493 & 0.228 & 0.000 & 0.000 \\
\hline EN-4 & 0.280 & 0.493 & 0.228 & 0.000 & 0.000 & 0.000 & 0.000 & 0.228 & 0.490 & 0.283 & 0.280 & 0.493 & 0.228 & 0.000 & 0.000 & 0.280 & 0.493 & 0.228 & 0.000 & 0.000 \\
\hline EN-5 & 0.280 & 0.493 & 0.228 & 0.000 & 0.000 & 0.000 & 0.144 & 0.394 & 0.355 & 0.107 & 0.280 & 0.493 & 0.228 & 0.000 & 0.000 & 0.319 & 0.478 & 0.203 & 0.000 & 0.000 \\
\hline EN-6 & 0.319 & 0.478 & 0.203 & 0.000 & 0.000 & 0.147 & 0.398 & 0.353 & 0.102 & 0.000 & 0.319 & 0.478 & 0.203 & 0.000 & 0.000 & 0.280 & 0.493 & 0.228 & 0.000 & 0.000 \\
\hline EN-7 & 0.064 & 0.315 & 0.436 & 0.186 & 0.000 & 0.000 & 0.000 & 0.166 & 0.458 & 0.376 & 0.028 & 0.279 & 0.473 & 0.220 & 0.000 & 0.104 & 0.353 & 0.396 & 0.147 & 0.000 \\
\hline EF-1 & 0.000 & 0.220 & 0.470 & 0.278 & 0.032 & 0.000 & 0.000 & 0.228 & 0.490 & 0.283 & 0.000 & 0.062 & 0.314 & 0.436 & 0.187 & 0.000 & 0.144 & 0.394 & 0.355 & 0.107 \\
\hline EF-2 & 0.000 & 0.000 & 0.040 & 0.368 & 0.591 & 0.000 & 0.000 & 0.201 & 0.477 & 0.322 & 0.000 & 0.027 & 0.277 & 0.471 & 0.225 & 0.000 & 0.077 & 0.330 & 0.432 & 0.161 \\
\hline EF-3 & 0.000 & 0.186 & 0.434 & 0.314 & 0.066 & 0.000 & 0.000 & 0.228 & 0.490 & 0.283 & 0.147 & 0.398 & 0.353 & 0.102 & 0.000 & 0.000 & 0.144 & 0.394 & 0.355 & 0.107 \\
\hline EF-4 & 0.000 & 0.000 & 0.166 & 0.458 & 0.376 & 0.000 & 0.000 & 0.128 & 0.433 & 0.439 & 0.000 & 0.062 & 0.314 & 0.436 & 0.187 & 0.000 & 0.000 & 0.128 & 0.433 & 0.439 \\
\hline EF-5 & 0.000 & 0.027 & 0.277 & 0.471 & 0.225 & 0.000 & 0.144 & 0.394 & 0.355 & 0.107 & 0.000 & 0.220 & 0.470 & 0.278 & 0.032 & 0.000 & 0.220 & 0.470 & 0.278 & 0.032 \\
\hline EF-6 & 0.000 & 0.062 & 0.314 & 0.436 & 0.187 & 0.000 & 0.027 & 0.277 & 0.471 & 0.225 & 0.000 & 0.062 & 0.314 & 0.436 & 0.187 & 0.000 & 0.000 & 0.082 & 0.400 & 0.518 \\
\hline EM-1 & 0.000 & 0.000 & 0.228 & 0.490 & 0.283 & 0.000 & 0.103 & 0.352 & 0.395 & 0.150 & 0.000 & 0.186 & 0.434 & 0.314 & 0.066 & 0.000 & 0.027 & 0.277 & 0.471 & 0.225 \\
\hline EM-2 & 0.000 & 0.027 & 0.277 & 0.471 & 0.225 & 0.000 & 0.062 & 0.314 & 0.436 & 0.187 & 0.000 & 0.144 & 0.394 & 0.355 & 0.107 & 0.000 & 0.027 & 0.277 & 0.471 & 0.225 \\
\hline EM-3 & 0.000 & 0.000 & 0.201 & 0.477 & 0.322 & 0.000 & 0.000 & 0.128 & 0.433 & 0.439 & 0.000 & 0.220 & 0.470 & 0.278 & 0.032 & 0.000 & 0.000 & 0.166 & 0.458 & 0.376 \\
\hline EM-4 & 0.000 & 0.000 & 0.082 & 0.400 & 0.518 & 0.000 & 0.000 & 0.082 & 0.400 & 0.518 & 0.000 & 0.027 & 0.277 & 0.471 & 0.225 & 0.000 & 0.000 & 0.082 & 0.400 & 0.518 \\
\hline EM-5 & 0.000 & 0.000 & 0.201 & 0.477 & 0.322 & 0.000 & 0.000 & 0.201 & 0.477 & 0.322 & 0.000 & 0.062 & 0.314 & 0.436 & 0.187 & 0.000 & 0.000 & 0.128 & 0.433 & 0.439 \\
\hline SA-1 & 0.000 & 0.000 & 0.082 & 0.400 & 0.518 & 0.000 & 0.031 & 0.287 & 0.476 & 0.206 & 0.028 & 0.279 & 0.473 & 0.220 & 0.000 & 0.000 & 0.062 & 0.314 & 0.436 & 0.187 \\
\hline SA-2 & 0.000 & 0.000 & 0.228 & 0.490 & 0.283 & 0.000 & 0.220 & 0.470 & 0.278 & 0.032 & 0.064 & 0.315 & 0.436 & 0.186 & 0.000 & 0.000 & 0.144 & 0.394 & 0.355 & 0.107 \\
\hline SA-3 & 0.000 & 0.000 & 0.040 & 0.368 & 0.591 & 0.000 & 0.062 & 0.314 & 0.436 & 0.187 & 0.000 & 0.144 & 0.394 & 0.355 & 0.107 & 0.000 & 0.000 & 0.082 & 0.400 & 0.518 \\
\hline SA-4 & 0.000 & 0.000 & 0.040 & 0.368 & 0.591 & 0.000 & 0.027 & 0.277 & 0.471 & 0.225 & 0.000 & 0.144 & 0.394 & 0.355 & 0.107 & 0.000 & 0.000 & 0.228 & 0.496 & 0.276 \\
\hline SA-5 & 0.000 & 0.000 & 0.040 & 0.368 & 0.591 & 0.000 & 0.000 & 0.228 & 0.490 & 0.283 & 0.000 & 0.062 & 0.314 & 0.436 & 0.187 & 0.000 & 0.000 & 0.082 & 0.400 & 0.518 \\
\hline
\end{tabular}




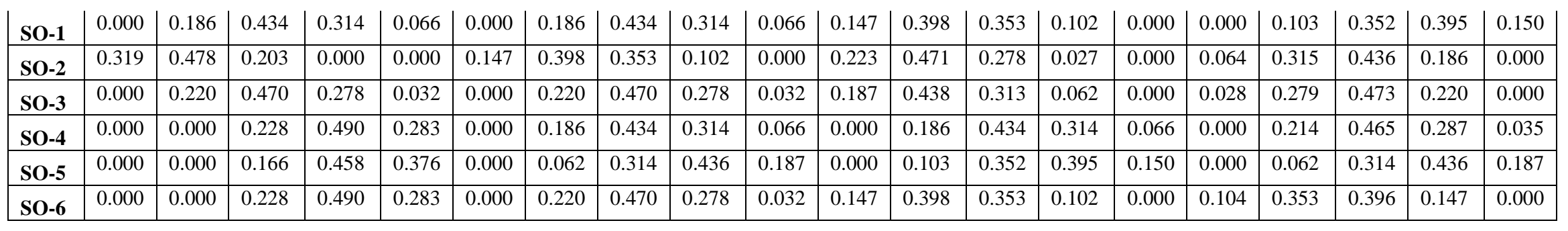




\subsection{Aggregation of Competitive Priorities through ERA}

The evidential reasoning algorithm is used to aggregate belief degrees of CSFs for all competitive priorities and hence to get a combined belief degree. The normalized belief degrees of all CSFs for each competitive priority are aggregated by using the ERA algorithm. For this purpose, IDS software (Yang and $\mathrm{Xu}, 1999)$ is utilized to compute competitive performance score (CPS) value for CSFs, and the computed outcomes are represented in Table 9. Moreover, to understand the aggregation part of ERA, a sample calculation for aggregation of belief degree for 'personnel training' (EC-2) is provided in Appendix-I.

\subsection{Use of Expected Utility Theory}

For assessing the performance of a system, it becomes more pragmatic to evaluate the considered factors on the basis of a crisp value. Thus, the concepts of expected utility are utilized to get a numerical value (i.e., CPS) for all CSFs of SFT. The CPS value of a CSF represents its priority level for achieving better competitive performance by an SFT system. The utility value for each assessment grade and CPS value for all CSFs is computed by using Equations (22) - (25).

Table 8 depicts that 'EC-1' obtains an overall CPS value of 0.7841 . This value shows the experts' evaluation for 'EC-1' when assessed on the basis of competitive priorities. 'EC-1' can be classified as a 'significant' CSF, which facilitates to achieve higher competitive performance. Further, by using the expected utility theorem, the crisp value of aggregated belief degrees for each CSF is calculated to get the CPS for all CSFs. Table 9 depicts the CPS value and rank of all CSFs. From Figure 3, it is evident that $8 \mathrm{CSFs}$ are considered as significant (represented by blue color); $18 \mathrm{CSF}$ are considered as moderately significant (represented by yellow color), and the remaining 8 CSFs are considered as slightly significant (represented by green color).

Table 8 Sample Calculation for CPS Value of EC-1

\begin{tabular}{|c|c|c|c|c|c|}
\hline$G_{n}$ & $\mathrm{VL}$ & $\mathrm{L}$ & $\mathrm{M}$ & $\mathrm{H}$ & $\mathrm{VH}$ \\
\hline$V_{n}$ & 1 & 2 & 3 & 4 & 5 \\
\hline$u\left(G_{n}\right)$ & $\frac{1-1}{5-1}=0$ & $\frac{2-1}{5-1}=0.25$ & $\frac{3-1}{5-1}=0.5$ & $\frac{4-1}{5-1}=0.75$ & $\frac{5-1}{5-1}=1$ \\
\hline$\beta_{n}$ & 0 & 0.0131 & 0.1804 & 0.4638 & 0.3428 \\
\hline$\sum_{n=1}^{5} \beta_{n}=0+0.0131+0.1804+0.4638+0.3428=1 \rightarrow \beta_{H}=0$ \\
\hline$u\left(G_{n}\right) \times \beta_{n}$ & 0 & 0.00327 & 0.0902 & 0.3478 & 0.3428 \\
\hline$\sum_{n=1}^{\mathbf{5}} u\left(G_{n}\right) \times \beta_{n}=\mathbf{C P S}_{\mathbf{E C}-1}=\mathbf{0 . 7 8 4 1}$ \\
\hline
\end{tabular}


Table 9 Competitive Performance Score of All CSFs

\begin{tabular}{|c|c|c|c|c|c|c|c|c|}
\hline \multirow[b]{2}{*}{ CSF } & \multicolumn{5}{|c|}{$\begin{array}{c}\text { Aggregated normalized belief degree for } \\
\text { competitive priorities }\end{array}$} & \multirow{2}{*}{$\begin{array}{l}\text { Competitive } \\
\text { Performance } \\
\text { Score (CPS) }\end{array}$} & \multirow[b]{2}{*}{ Rank } & \multirow[t]{2}{*}{ Classification } \\
\hline & VL & $\mathbf{L}$ & $\mathbf{M}$ & $\mathbf{H}$ & VH & & & \\
\hline EC-1 & 0.000 & 0.013 & 0.180 & 0.464 & 0.343 & 0.784 & 5 & Significant \\
\hline EC-2 & 0.000 & 0.000 & 0.119 & 0.447 & 0.434 & 0.829 & 2 & Significant \\
\hline EC-3 & 0.051 & 0.232 & 0.388 & 0.258 & 0.070 & 0.516 & 25 & Moderately significant \\
\hline EC-4 & 0.000 & 0.060 & 0.304 & 0.447 & 0.188 & 0.691 & 14 & Moderately significant \\
\hline EC-5 & 0.000 & 0.037 & 0.274 & 0.478 & 0.212 & 0.716 & 12 & Moderately significant \\
\hline EN-1 & 0.189 & 0.401 & 0.264 & 0.104 & 0.042 & 0.352 & 29 & Slightly significant \\
\hline EN-2 & 0.237 & 0.416 & 0.245 & 0.078 & 0.024 & 0.309 & 33 & Slightly significant \\
\hline EN-3 & 0.166 & 0.413 & 0.314 & 0.093 & 0.014 & 0.344 & 30 & Slightly significant \\
\hline EN-4 & 0.207 & 0.390 & 0.229 & 0.110 & 0.063 & 0.358 & 28 & Slightly significant \\
\hline EN-5 & 0.212 & 0.425 & 0.261 & 0.078 & 0.023 & 0.319 & 32 & Slightly significant \\
\hline EN-6 & 0.255 & 0.489 & 0.234 & 0.022 & 0.000 & 0.255 & 34 & Slightly significant \\
\hline EN-7 & 0.044 & 0.233 & 0.388 & 0.251 & 0.083 & 0.524 & 24 & Moderately significant \\
\hline EF-1 & 0.000 & 0.096 & 0.359 & 0.406 & 0.140 & 0.647 & 18 & Moderately significant \\
\hline EF-2 & 0.000 & 0.022 & 0.198 & 0.460 & 0.319 & 0.769 & 7 & Significant \\
\hline EF-3 & 0.032 & 0.173 & 0.369 & 0.322 & 0.105 & 0.573 & 22 & Moderately significant \\
\hline EF-4 & 0.000 & 0.013 & 0.168 & 0.459 & 0.360 & 0.791 & 4 & Significant \\
\hline EF-5 & 0.000 & 0.141 & 0.421 & 0.351 & 0.088 & 0.597 & 20 & Moderately significant \\
\hline EF-6 & 0.000 & 0.033 & 0.236 & 0.460 & 0.271 & 0.742 & 10 & Moderately significant \\
\hline EM-1 & 0.000 & 0.070 & 0.323 & 0.439 & 0.168 & 0.676 & 17 & Moderately significant \\
\hline EM-2 & 0.000 & 0.057 & 0.314 & 0.456 & 0.174 & 0.687 & 15 & Moderately significant \\
\hline EM-3 & 0.000 & 0.047 & 0.232 & 0.434 & 0.287 & 0.740 & 11 & Moderately significant \\
\hline EM-4 & 0.000 & 0.006 & 0.114 & 0.424 & 0.456 & 0.833 & 1 & Significant \\
\hline EM-5 & 0.000 & 0.013 & 0.196 & 0.480 & 0.311 & 0.772 & 6 & Significant \\
\hline SA-1 & 0.006 & 0.084 & 0.289 & 0.404 & 0.218 & 0.686 & 16 & Moderately significant \\
\hline SA-2 & 0.014 & 0.159 & 0.400 & 0.333 & 0.095 & 0.584 & 21 & Moderately significant \\
\hline SA-3 & 0.000 & 0.045 & 0.195 & 0.407 & 0.353 & 0.767 & 8 & Significant \\
\hline SA-4 & 0.000 & 0.037 & 0.224 & 0.446 & 0.293 & 0.749 & 9 & Moderately significant \\
\hline SA-5 & 0.000 & 0.013 & 0.150 & 0.438 & 0.399 & 0.806 & 3 & Significant \\
\hline SO-1 & 0.032 & 0.210 & 0.416 & 0.280 & 0.063 & 0.533 & 23 & Moderately significant \\
\hline SO-2 & 0.176 & 0.437 & 0.318 & 0.070 & 0.000 & 0.320 & 31 & Slightly significant \\
\hline SO-3 & 0.047 & 0.285 & 0.457 & 0.198 & 0.014 & 0.462 & 27 & Slightly significant \\
\hline SO-4 & 0.000 & 0.135 & 0.406 & 0.359 & 0.101 & 0.606 & 19 & Moderately significant \\
\hline SO-5 & 0.000 & 0.050 & 0.281 & 0.455 & 0.214 & 0.708 & 13 & Moderately significant \\
\hline SO-6 & 0.057 & 0.239 & 0.382 & 0.252 & 0.070 & 0.510 & 26 & Moderately significant \\
\hline
\end{tabular}




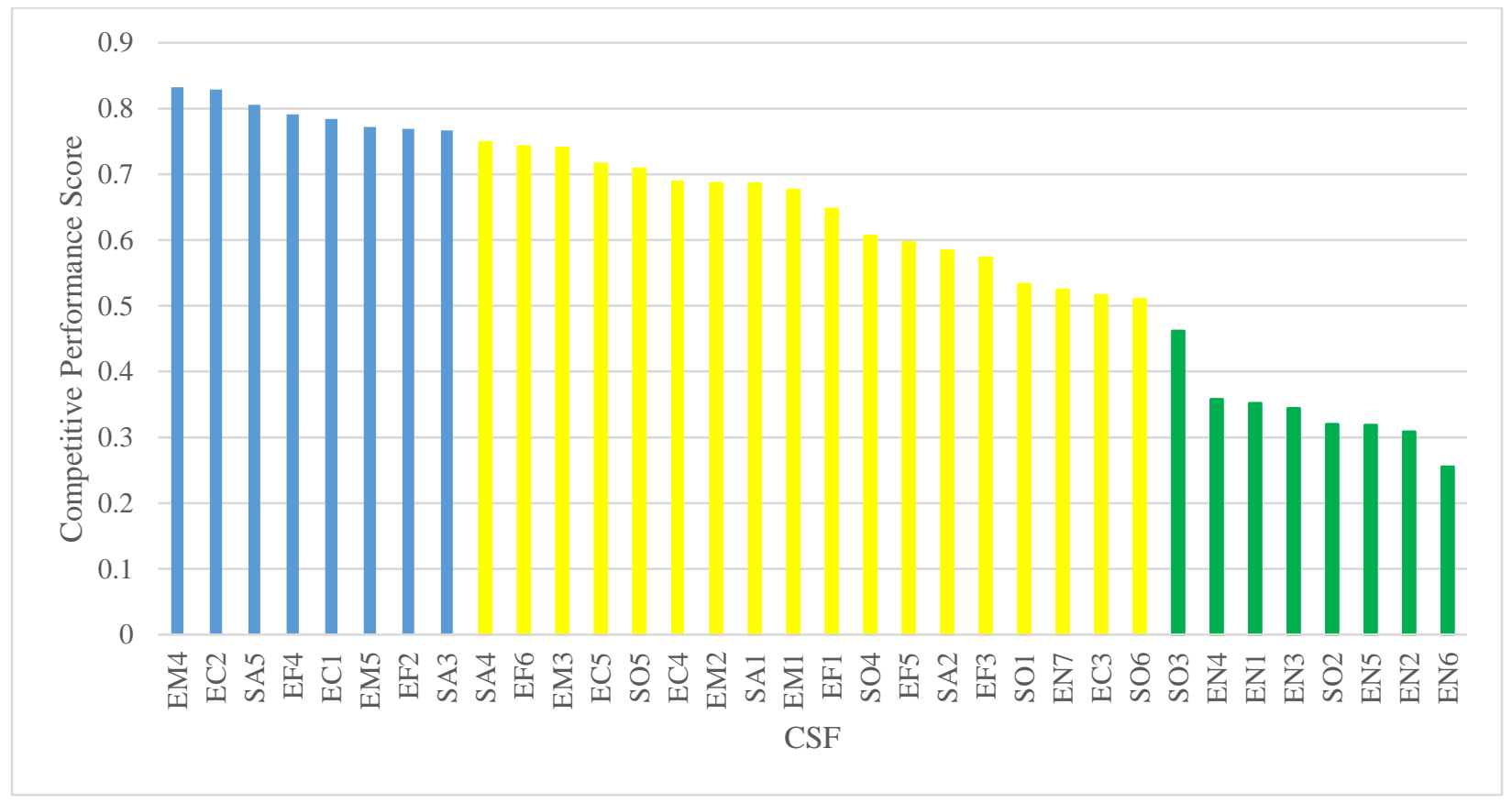

Figure 3 Competitive Performance Order of CSFs of SFT

\subsection{CPS Calculation for Each Category of SFT}

After obtaining an aggregated normalized belief degree of competitive priorities for all CSFs, similar calculations are performed using Equations (13) - (20) to get a normalized belief degree for the six dimensions of SFT by aggregating normalized belief degree of all CSFs under each sustainability dimension. Table 10 depicts the normalized belief degree and classification of six dimensions of SFT based on CPS.

Table 10 CPS Calculation for Six Dimensions of SFT

\begin{tabular}{|c|c|c|c|c|c|c|c|c|}
\hline \multirow{2}{*}{$\begin{array}{l}\text { Sustainability } \\
\text { Factors/ } \\
\text { Dimensions }\end{array}$} & \multicolumn{5}{|c|}{$\begin{array}{c}\text { Aggregated normalized belief degree of } \\
\text { competitive priorities }\end{array}$} & \multirow{2}{*}{$\begin{array}{l}\text { Competitive } \\
\text { Performance } \\
\text { Score }\end{array}$} & \multirow[b]{2}{*}{ Rank } & \multirow[b]{2}{*}{ Classificatior } \\
\hline & VL & $\mathbf{L}$ & $\mathbf{M}$ & $\mathbf{H}$ & VH & & & \\
\hline $\mathrm{EC}$ & 0.009 & 0.060 & 0.246 & 0.444 & 0.241 & 0.712 & 3 & $\begin{array}{r}\text { Moderately } \\
\text { significant }\end{array}$ \\
\hline $\mathrm{EN}$ & 0.178 & 0.418 & 0.276 & 0.096 & 0.032 & 0.346 & 6 & $\begin{array}{c}\text { Slightly } \\
\text { significant }\end{array}$ \\
\hline$\overline{E F}$ & 0.005 & 0.071 & 0.289 & 0.432 & 0.203 & 0.690 & 4 & $\begin{array}{r}\text { Moderately } \\
\text { significant }\end{array}$ \\
\hline EM & 0.000 & 0.033 & 0.224 & 0.473 & 0.270 & 0.745 & 1 & Significant \\
\hline $\mathrm{SA}$ & 0.003 & 0.060 & 0.244 & 0.427 & 0.266 & 0.723 & 2 & $\begin{array}{r}\text { Moderately } \\
\text { significant }\end{array}$ \\
\hline $\mathrm{SO}$ & 0.046 & 0.220 & 0.398 & 0.267 & 0.069 & 0.523 & 5 & $\begin{array}{r}\text { Moderately } \\
\text { significant }\end{array}$ \\
\hline
\end{tabular}


From Table 10, it is evident that 'employing advanced technology dimension' (EM) is the most significant dimension with 0.745 CPS value. 'Safety dimension' (SA), 'economic dimension' (EC), ‘efficiency dimension' (EF), ‘social dimension' (SO), and ‘environmental dimension' (EN) attain the second, third, fourth, fifth, and sixth position, respectively, with $0.723,0.712,0.69,0.523$, and 0.346 CPS value. The CPS value depicts the experts' assessment of sustainability factors based on competitive priorities for FT systems. The outcomes from Table 9 represent that CPS value for all CSFs is more than 0.24, and thus, no CSF falls in the class of 'not significant at all' category. This study assists decision-makers in carrying out performance analysis for SFT based on competitive priorities and identify the key CSFs and dimensions of SFT for improving competitive performance. The considered procedure in this study depicts a viable approach for performance analysis of SFT systems on the basis of competitive priorities when objective or statistical data is not available.

\section{SENSITIVITY ANALYSIS}

The sensitivity analysis is carried out by employing the three axioms discussed in Section 3.4.4. These axioms facilitate to identify the most significant CSFs and sustainability dimensions that lead to a better competitive performance by an SFT system. To perform the sensitivity analysis, belief degrees related to the most preferred assessment term of the lowest level criteria (i.e., competitive priorities) are decreased by $a$, and then CPS values are computed for each CSF. It is significant to highlight that when lessening the belief degree, $\beta_{n}$, of the most preferred assessment term of a criterion by $a$, if $a>\beta_{n}$, the residual belief degree (i.e., $a-\beta_{n}$ ) is reduced from the belief degree of the next assessment term until $a$ is completely exhausted (John et al., 2014).

The computed utility values (i.e., CPS values) after carrying out different experiments (i.e., lessening the belief degrees of the most favored assessment term (by 10\%, 20\%, and 30\%, respectively) of all competitive priorities) are depicted in Table 11. The sensitivity of the obtained results for all CSFs is explicated in Table 11. These outcomes completely satisfy Axioms 1 and 2 (as discussed in Section 3.4.4). 
Table 11 Sensitivity Analysis by Changing Belief Degrees

\begin{tabular}{|c|c|c|c|c|c|c|c|c|c|c|c|c|c|c|c|c|}
\hline & \multicolumn{4}{|c|}{ DQ } & \multicolumn{4}{|c|}{ IN } & \multicolumn{4}{|c|}{$\mathrm{CO}$} & \multicolumn{4}{|c|}{ FL } \\
\hline & $0 \%$ & $10 \%$ & $20 \%$ & $30 \%$ & $0 \%$ & $10 \%$ & $20 \%$ & $30 \%$ & $0 \%$ & $10 \%$ & $20 \%$ & $30 \%$ & $0 \%$ & $10 \%$ & $20 \%$ & $30 \%$ \\
\hline & & & & & & & & 0.61 & 0.88 & 0.83 & 0.78 & 0.73 & 0.78 & 0.73 & 0.68 & 0.63 \\
\hline EC-1 & 0.687 & 0.613 & 0.541 & 0.491 & 0.764 & 0.714 & 0.664 & 8 & 8 & 8 & 8 & 8 & 0 & 0 & 0 & 0 \\
\hline & & & & & & & & 0.65 & 0.85 & 0.80 & 0.75 & 0.70 & 0.80 & 0.75 & 0.70 & 0.65 \\
\hline EC-2 & 0.828 & 0.778 & 0.728 & 0.678 & 0.802 & 0.753 & 0.703 & 3 & 9 & 9 & 9 & 9 & 2 & 3 & 3 & 3 \\
\hline & & & & & & & & 0.17 & 0.76 & 0.71 & 0.66 & 0.61 & 0.53 & 0.47 & 0.42 & 0.37 \\
\hline EC-3 & 0.419 & 0.344 & 0.277 & 0.227 & 0.353 & 0.278 & 0.227 & 7 & 4 & 4 & 4 & 8 & 1 & 3 & 3 & 3 \\
\hline & & & & & & & & 0.49 & 0.72 & 0.64 & 0.57 & 0.51 & 0.56 & 0.49 & 0.44 & 0.39 \\
\hline EC-4 & 0.780 & 0.730 & 0.680 & 0.630 & 0.687 & 0.613 & 0.541 & 1 & 3 & 9 & 4 & 7 & 5 & 9 & 9 & 9 \\
\hline & & & & & & & & 0.61 & 0.72 & 0.64 & 0.57 & 0.51 & 0.60 & 0.53 & 0.48 & 0.43 \\
\hline EC-5 & 0.764 & 0.714 & 0.664 & 0.618 & 0.764 & 0.714 & 0.664 & 8 & 3 & 9 & 4 & 7 & 6 & 1 & 0 & 0 \\
\hline & & & & & & & & 0.49 & 0.27 & 0.22 & 0.17 & 0.12 & 0.23 & 0.18 & 0.13 & 0.10 \\
\hline EN-1 & 0.237 & 0.187 & 0.137 & 0.105 & 0.687 & 0.613 & 0.541 & 1 & 8 & 1 & 1 & 1 & 7 & 7 & 7 & 5 \\
\hline & & & & & & & & 0.43 & 0.23 & 0.18 & 0.13 & 0.10 & 0.22 & 0.17 & 0.12 & 0.09 \\
\hline EN-2 & 0.199 & 0.149 & 0.107 & 0.082 & 0.606 & 0.531 & 0.480 & $\begin{array}{r}0.4 \\
0\end{array}$ & $\begin{array}{r}7 \\
\end{array}$ & $\begin{array}{r}7.10 \\
\end{array}$ & 7 & 5 & $\begin{array}{r}.22 \\
1\end{array}$ & $\begin{array}{r}1.17 \\
\end{array}$ & $\begin{array}{r}1 \\
\end{array}$ & $\begin{array}{r}5 \\
\end{array}$ \\
\hline & & & & & & & & 0.39 & 0.23 & 0.18 & 0.13 & 0.10 & 0.23 & 0.18 & 0.13 & 0.10 \\
\hline EN-3 & 0.353 & 0.278 & 0.227 & 0.177 & 0.565 & 0.499 & 0.449 & 9 & 7 & 7 & 7 & 5 & 7 & 7 & 7 & 5 \\
\hline & & & & & & & & 0.61 & 0.23 & 0.18 & 0.13 & 0.10 & 0.23 & 0.18 & 0.13 & 0.10 \\
\hline EN-4 & 0.237 & 0.187 & 0.137 & 0.105 & 0.764 & 0.714 & 0.664 & 8 & 7 & 7 & 7 & 5 & 7 & 7 & 7 & 5 \\
\hline & & & & & & & & 0.43 & 0.23 & 0.18 & 0.13 & 0.10 & 0.22 & 0.17 & 0.12 & 0.09 \\
\hline EN-5 & 0.237 & 0.187 & 0.137 & 0.105 & 0.606 & 0.531 & 0.480 & 0 & 7 & 7 & 7 & 5 & 1 & 1 & 1 & 5 \\
\hline & & & & & & & & 0.17 & 0.22 & 0.17 & 0.12 & 0.09 & 0.23 & 0.18 & 0.13 & 0.10 \\
\hline EN-6 & 0.221 & 0.171 & 0.121 & 0.095 & 0.353 & 0.278 & 0.227 & 7 & 1 & 1 & 1 & 5 & 7 & 7 & 7 & 5 \\
\hline & & & & & & & & 0.65 & 0.47 & 0.39 & 0.32 & 0.26 & 0.39 & 0.32 & 0.26 & 0.21 \\
\hline EN-7 & 0.436 & 0.361 & 0.289 & 0.239 & 0.802 & 0.753 & 0.703 & 3 & 1 & 6 & 1 & 6 & 6 & 2 & 0 & 0 \\
\hline & & & & & & & & 0.61 & 0.68 & 0.61 & 0.54 & 0.49 & 0.60 & 0.53 & 0.48 & 0.43 \\
\hline EF-1 & 0.531 & 0.473 & 0.423 & 0.373 & 0.764 & 0.714 & 0.664 & 8 & 7 & 3 & 1 & 1 & 6 & 1 & 0 & 0 \\
\hline & & & & & & & & 0.63 & 0.72 & 0.64 & 0.57 & 0.51 & 0.66 & 0.59 & 0.52 & 0.47 \\
\hline EF-2 & 0.888 & 0.838 & 0.788 & 0.738 & 0.780 & 0.730 & 0.680 & 0 & 3 & 9 & 4 & 7 & 9 & 4 & 9 & 9 \\
\hline & & & & & & & & 0.61 & 0.35 & 0.27 & 0.22 & 0.17 & 0.60 & 0.53 & 0.48 & 0.43 \\
\hline EF-3 & 0.565 & 0.499 & 0.449 & 0.399 & 0.764 & 0.714 & 0.664 & 8 & 3 & 8 & 7 & 7 & 6 & 1 & 0 & 0 \\
\hline & & & & & & & & 0.67 & 0.68 & 0.61 & 0.54 & 0.49 & 0.82 & 0.77 & 0.72 & 0.67 \\
\hline EF-4 & 0.802 & 0.753 & 0.703 & 0.653 & 0.828 & 0.778 & 0.728 & 8 & 7 & 3 & 1 & 1 & 8 & 8 & 8 & 8 \\
\hline & & & & & & & & 0.43 & 0.53 & 0.47 & 0.42 & 0.37 & 0.53 & 0.47 & 0.42 & 0.37 \\
\hline EF-5 & 0.723 & 0.649 & 0.574 & 0.517 & 0.606 & 0.531 & 0.480 & 0 & 1 & 3 & 3 & 3 & 1 & 3 & 3 & 3 \\
\hline & & & & & & & & 0.51 & 0.68 & 0.61 & 0.54 & 0.49 & 0.85 & 0.80 & 0.75 & 0.70 \\
\hline EF-6 & 0.687 & 0.613 & 0.541 & 0.491 & 0.723 & 0.649 & 0.574 & 7 & 7 & 3 & 1 & 1 & 9 & 9 & 9 & 9 \\
\hline & & & & & & & & 0.46 & 0.56 & 0.49 & 0.44 & 0.39 & 0.72 & 0.64 & 0.57 & 0.51 \\
\hline EM-1 & 0.764 & 0.714 & 0.664 & 0.618 & 0.648 & 0.573 & 0.511 & 1 & 5 & 9 & 9 & 9 & 3 & 9 & 4 & 7 \\
\hline & & & & & & & & 0.49 & 0.60 & 0.53 & 0.48 & 0.43 & 0.72 & 0.64 & 0.57 & 0.51 \\
\hline EM-2 & 723 & 0.649 & 0.574 & 0.517 & 0.687 & 0.613 & 0.541 & 1 & 6 & 1 & 0 & 0 & 3 & 9 & 4 & 7 \\
\hline & & & & & & & & 0.67 & 0.53 & 0.47 & 0.42 & 0.37 & 0.80 & 0.75 & 0.70 & 0.65 \\
\hline EM-3 & 0.780 & 0.730 & 0.680 & 0.630 & 0.828 & 0.778 & 0.728 & 8 & 1 & 3 & 3 & 3 & 2 & 3 & 3 & 3 \\
\hline & & & & & & & & 0.70 & 0.72 & 0.64 & 0.57 & 0.51 & 0.85 & 0.80 & 0.75 & 0.70 \\
\hline EM-4 & 0.859 & 0.809 & 0.759 & 0.709 & 0.859 & 0.809 & 0.759 & 9 & 3 & 9 & 4 & 7 & 9 & 9 & 9 & 9 \\
\hline & & & & & & & & 0.63 & 0.68 & 0.61 & 0.54 & 0.49 & 0.82 & 0.77 & 0.72 & 0.67 \\
\hline EM-5 & 0.780 & 0.730 & 0.680 & 0.630 & 0.780 & 0.730 & 0.680 & 0 & 7 & 3 & 1 & 1 & 8 & 8 & 8 & 8 \\
\hline & & & & & & & & 0.51 & 0.47 & 0.39 & 0.32 & 0.26 & 0.68 & 0.61 & 0.54 & 0.49 \\
\hline SA-1 & 0.859 & 0.809 & 0.759 & 0.709 & 0.714 & 0.639 & 0.564 & 3 & 1 & 6 & 1 & 6 & 7 & 3 & 1 & 1 \\
\hline & & & & & & & & 0.37 & 0.43 & 0.36 & 0.28 & 0.23 & 0.60 & 0.53 & 0.48 & 0.43 \\
\hline SA-2 & 0.764 & 0.714 & 0.664 & 0.618 & 0.531 & 0.473 & 0.423 & 3 & 6 & 1 & 9 & 9 & 6 & 1 & 0 & 0 \\
\hline & & & & & & & & 0.49 & 0.60 & 0.53 & 0.48 & 0.43 & 0.85 & 0.80 & 0.75 & 0.70 \\
\hline SA-3 & 0.888 & 0.838 & 0.788 & 0.738 & 0.687 & 0.613 & 0.541 & 1 & 6 & 1 & 0 & 0 & 9 & 9 & 9 & 9 \\
\hline & & & & & & & & 0.51 & 0.60 & 0.53 & 0.48 & 0.43 & 0.76 & 0.71 & 0.66 & 0.61 \\
\hline SA-4 & 0.888 & 0.838 & 0.788 & 0.738 & 0.723 & 0.649 & 0.574 & 7 & 6 & 1 & 0 & 0 & 2 & 2 & 2 & 8 \\
\hline & & & & & & & & 0.61 & 0.68 & 0.61 & 0.54 & 0.49 & 0.85 & 0.80 & 0.75 & 0.70 \\
\hline SA-5 & 0.888 & 0.838 & 0.788 & 0.738 & 0.764 & 0.714 & 0.664 & 8 & 7 & 3 & 1 & 1 & 9 & 9 & 9 & 9 \\
\hline & & & & & & & & 0.39 & 0.35 & 0.27 & 0.22 & 0.17 & 0.64 & 0.57 & 0.51 & 0.46 \\
\hline SO-1 & 0.565 & 0.499 & 0.449 & 0.399 & 0.565 & 0.499 & 0.449 & 9 & 3 & 8 & 7 & 7 & 8 & 3 & 1 & 1 \\
\hline & & & & & & & & 0.17 & 0.27 & 0.22 & 0.17 & 0.12 & 0.43 & 0.36 & 0.28 & 0.23 \\
\hline SO-2 & 0.221 & 0.171 & 0.121 & 0.095 & 0.353 & 0.278 & 0.227 & 7 & 8 & 1 & 1 & 1 & 6 & 1 & 9 & 9 \\
\hline & & & & & & & & 0.37 & 0.31 & 0.24 & 0.19 & 0.14 & 0.47 & 0.39 & 0.32 & 0.26 \\
\hline SO-3 & 0.531 & 0.473 & 0.423 & 0.373 & 0.531 & 0.473 & 0.423 & 3 & 3 & 7 & 7 & 7 & 1 & 6 & 1 & 6 \\
\hline & & & & & & & & 0.39 & 0.56 & 0.49 & 0.44 & 0.39 & 0.53 & 0.47 & 0.42 & 0.37 \\
\hline SO-4 & 0.764 & 0.714 & 0.664 & 0.618 & 0.565 & 0.499 & 0.449 & 9 & 5 & 9 & 9 & 9 & 6 & 7 & 7 & 7 \\
\hline & & & & & & & & 0.49 & 0.64 & 0.57 & 0.51 & 0.46 & 0.68 & 0.61 & 0.54 & 0.49 \\
\hline SO-5 & 0.802 & 0.753 & 0.703 & 0.653 & 0.687 & 0.613 & 0.541 & 1 & 8 & 3 & 1 & 1 & 7 & 3 & 1 & 1 \\
\hline & & & & & & & & 0.37 & 0.35 & 0.27 & 0.22 & 0.17 & 0.39 & 0.32 & 0.26 & 0.21 \\
\hline SO-6 & 0.764 & 0.714 & 0.664 & 0.618 & 0.531 & 0.473 & 0.423 & 3 & 3 & 8 & 7 & 7 & 6 & 2 & 0 & 0 \\
\hline
\end{tabular}


Subsequently, we investigate the impact of the variations in belief degree of the lowest-level criteria (i.e., all competitive priorities) on the CPS value of six dimensions of SFT. The changes represent several combinations of the lowest-level criteria. Table 12 illustrates 16 distinct combinations of variation in the lowest level criteria (i.e., competitive priorities) and their impact on the CPS value of six dimensions of SFT. According to Axiom 3, if the model represents robustness, rationality, and reality, the CPS value of the six dimensions of SFT related to $x$ criteria (i.e., evidence) should be lesser than the one from $x-y(y \in x)$ criteria (i.e., sub-evidence). This requirement is analyzed by examining the CPS values of the six dimensions of SFT, as depicted in Table 12. For instance, we take Row 13 as evidence to examine the robustness of the proposed model. Then, Rows 2, 3, 4, 7, 10, and 11 can be considered as the sub-evidence. Comparing the relevant CPS values of the six dimensions of SFT (e.g., CPS value of 'EC' in Row 13 is 0.665 , that is lesser than 0.681, the one in Row 11), it is apparent that for Row 13, the proposed model is confirmed to be robust. Likewise, each row of Table 12 is examined carefully, and the outcomes of the proposed model are in harmony with Axiom 3.

Table 12 Sensitivity Analysis by Changing Belief Degree of Lowest Level Criteria

\begin{tabular}{|c|c|c|c|c|c|c|c|c|c|c|}
\hline & \multirow[b]{2}{*}{ DQ } & \multirow[b]{2}{*}{ IN } & \multirow[b]{2}{*}{$\mathrm{CO}$} & \multirow[b]{2}{*}{ FL } & \multicolumn{6}{|c|}{ Competitive Priority Score } \\
\hline & & & & & EC & $\mathbf{E N}$ & EF & EM & $\mathbf{S A}$ & SO \\
\hline 1 & 0 & 0 & 0 & 0 & 0.712 & 0.346 & 0.690 & 0.745 & 0.723 & 0.523 \\
\hline 2 & 1 & 0 & 0 & 0 & 0.696 & 0.330 & 0.674 & 0.730 & 0.708 & 0.511 \\
\hline 3 & 0 & 1 & 0 & 0 & 0.696 & 0.332 & 0.674 & 0.729 & 0.706 & 0.507 \\
\hline 4 & 0 & 0 & 1 & 0 & 0.696 & 0.331 & 0.672 & 0.729 & 0.705 & 0.507 \\
\hline 5 & 0 & 0 & 0 & 1 & 0.696 & 0.331 & 0.673 & 0.729 & 0.706 & 0.506 \\
\hline 6 & 0 & 1 & 0 & 1 & 0.681 & 0.317 & 0.658 & 0.713 & 0.689 & 0.489 \\
\hline 7 & 0 & 1 & 1 & 0 & 0.681 & 0.317 & 0.657 & 0.713 & 0.688 & 0.490 \\
\hline 8 & 0 & 1 & 1 & 1 & 0.665 & 0.301 & 0.641 & 0.697 & 0.671 & 0.471 \\
\hline 9 & 0 & 0 & 1 & 1 & 0.681 & 0.315 & 0.656 & 0.713 & 0.689 & 0.489 \\
\hline 10 & 1 & 1 & 0 & 0 & 0.681 & 0.316 & 0.658 & 0.714 & 0.691 & 0.493 \\
\hline 11 & 1 & 0 & 1 & 0 & 0.681 & 0.314 & 0.656 & 0.714 & 0.691 & 0.493 \\
\hline 12 & 1 & 0 & 0 & 1 & 0.681 & 0.315 & 0.657 & 0.714 & 0.692 & 0.493 \\
\hline 13 & 1 & 1 & 1 & 0 & 0.665 & 0.301 & 0.641 & 0.698 & 0.673 & 0.477 \\
\hline 14 & 1 & 1 & 0 & 1 & 0.665 & 0.301 & 0.642 & 0.699 & 0.675 & 0.475 \\
\hline 15 & 1 & 0 & 1 & 1 & 0.665 & 0.298 & 0.639 & 0.698 & 0.674 & 0.476 \\
\hline 16 & 1 & 1 & 1 & 1 & 0.650 & 0.285 & 0.625 & 0.683 & 0.657 & 0.459 \\
\hline
\end{tabular}

Note: "1" means that a $10 \%$ belief degree is redistributed (i.e., from the most favored assessment term to the least favored assessment term) for each competitive priority 
Afterward, to graphically show the results of sensitivity analysis, the aggregated normalized belief degree of competitive priorities is computed for all CSFs by aggregating normalized belief degree of individual competitive priority using ERA. Then, this aggregated normalized belief degree for competitive priorities (as represented in Table 9) is varied by $10 \%, 20 \%$, and $30 \%$. The sensitivity of the obtained results for all CSFs is graphically presented in Figure 4. From Table 11 and Table 12, it is evident that the proposed model completely satisfies all three axioms of sensitivity analysis (John et al., 2014; Wan et al., 2019; Yang et al., 2009).

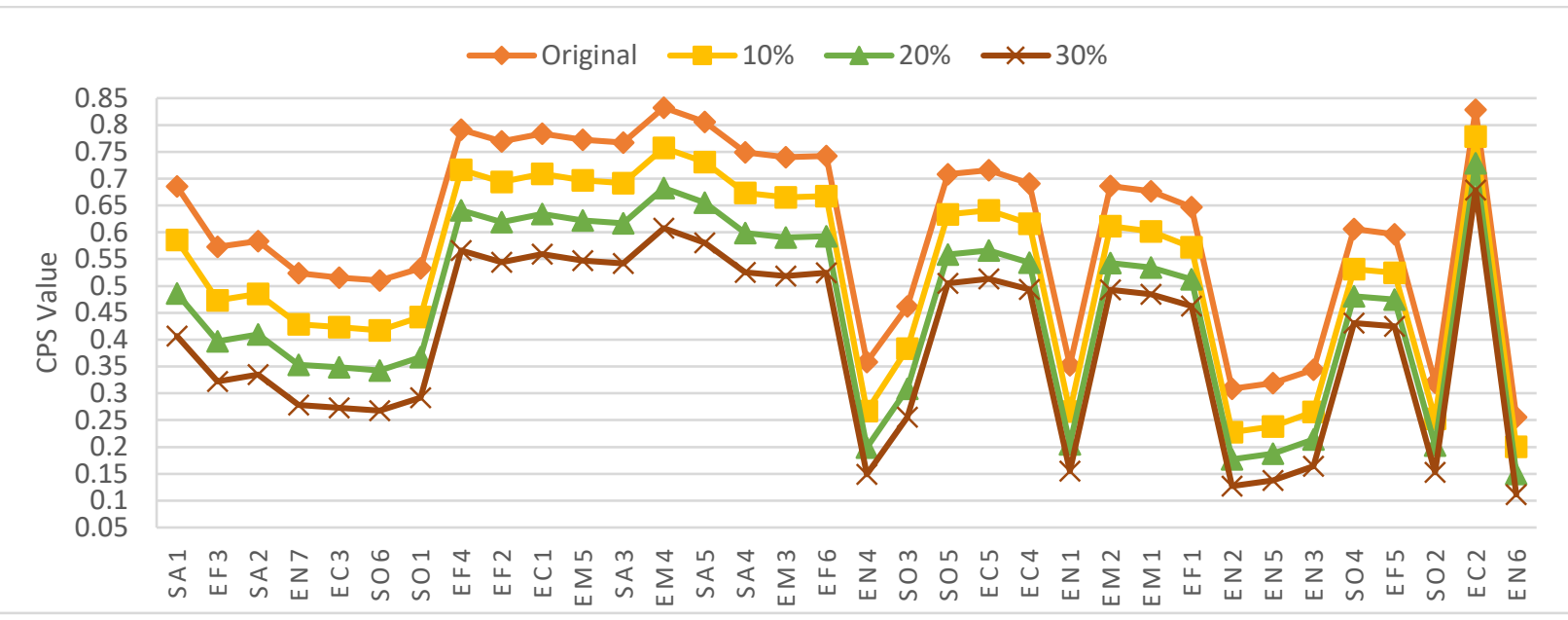

Figure 4 Sensitivity of CPS Value to the Variation in Aggregated Normalized Belief Degrees of Competitive Priorities

\section{EFFECT OF VARIATIONS IN THE WEIGHT OF COMPETITIVE PRIORITIES}

This paper also analyzes the effect of variations in the weight of competitive priorities to bring out the key sustainability dimensions that lead to attaining higher competitive advantage for different weight allocation scenarios. While calculating the aggregated normalized belief degrees for all CSFs, it is considered that the significance of each competitive priority for the performance assessment is the same. Therefore, equal weight was allotted to them. Ramani et al. (2011) signify that, in an MCDM problem, weight distribution has always been challenging as weight allocation usually affects outcomes. Therefore, to examine the effect of variations in the weight of each competitive priority on the CPS value of six dimensions of SFT, we vary weight on a scale of 0 to 1 (with an interval of 0.2 ) and repeat the entire analysis for different weights. When a particular value of weight is assigned to a competitive priority, the other three competitive priorities will have equal normalized weight. For instance, If 
'delivery of quality services' (DQ) is allotted a weight of 0.4 , the other three competitive priorities (i.e., 'innovation' (IN), 'cost' (CO), and 'flexibility' (FL)) will have an equal normalized weight of 0.2. The effect of variation in weight of each competitive priority (i.e., DQ, IN, CO, and FL) on the CPS value of six dimensions of SFT is depicted in Table 13. 
Table 13 Categorization of Six Dimensions of SFT Based on the Variation in Weights of Each Competitive Priority

\begin{tabular}{|c|c|c|c|c|c|c|c|c|c|c|c|c|c|c|c|c|c|c|c|c|c|c|c|c|c|}
\hline \multirow{3}{*}{$\begin{array}{l}\text { Dimens } \\
\text { ions of } \\
\text { SFT }\end{array}$} & \multirow{3}{*}{$\begin{array}{c}\text { Origi } \\
\text { nal } \\
\text { CPS }\end{array}$} & \multicolumn{24}{|c|}{ CPS values due to the variations in the weight of } \\
\hline & & \multicolumn{6}{|c|}{ DQ } & \multicolumn{6}{|c|}{ IN } & \multicolumn{6}{|c|}{$\mathrm{CO}$} & \multicolumn{6}{|c|}{ FL } \\
\hline & & $\mathbf{0}$ & 0.2 & 0.4 & 0.6 & 0.8 & 1 & $\mathbf{0}$ & 0.2 & 0.4 & 0.6 & 0.8 & 1 & $\mathbf{0}$ & 0.2 & 0.4 & 0.6 & 0.8 & 1 & $\mathbf{0}$ & 0.2 & 0.4 & 0.6 & 0.8 & 1 \\
\hline \multirow{2}{*}{ EC } & & 0.7 & 0.7 & 0.7 & 0.7 & 0.7 & 0.7 & 0.7 & 0.7 & 0.7 & 0.6 & 0.6 & 0.6 & 0.6 & 0.7 & 0.7 & 0.7 & 0.7 & 0.7 & 0.7 & 0.7 & 0.6 & 0.6 & 0.6 & 0.6 \\
\hline & 0.712 & 15 & 12 & 10 & 06 & 03 & 01 & 22 & 14 & 04 & 92 & 84 & 81 & 82 & 04 & 36 & 68 & 89 & 96 & 29 & 16 & 98 & 78 & 64 & 58 \\
\hline \multirow[b]{2}{*}{ EN } & & 0.3 & 0.3 & 0.3 & 0.2 & 0.2 & 0.2 & 0.2 & 0.3 & 0.4 & 0.5 & 0.6 & 0.6 & 0.3 & 0.3 & 0.3 & 0.2 & 0.2 & 0.2 & 0.3 & 0.3 & 0.3 & 0.2 & 0.2 & 0.2 \\
\hline & 0.346 & 74 & 53 & 24 & 95 & 78 & 71 & 64 & 24 & 24 & 33 & 05 & 29 & 74 & 53 & 23 & 95 & 78 & 72 & 81 & 54 & 18 & 83 & 61 & 53 \\
\hline \multirow[b]{2}{*}{ EF } & & 0.6 & 0.6 & 0.6 & 0.6 & 0.7 & 0.7 & 0.6 & 0.6 & 0.7 & 0.7 & 0.7 & 0.7 & 0.7 & 0.6 & 0.6 & 0.6 & 0.6 & 0.6 & 0.6 & 0.6 & 0.6 & 0.6 & 0.6 & 0.6 \\
\hline & 0.69 & 85 & 89 & 94 & 99 & 01 & 02 & 69 & 85 & 06 & 28 & 42 & 47 & 14 & 96 & 69 & 42 & 22 & 14 & 90 & 90 & 89 & 88 & 86 & 85 \\
\hline \multirow[b]{2}{*}{ EM } & & 0.7 & 0.7 & 0.7 & 0.7 & 0.7 & 0.7 & 0.7 & 0.7 & 0.7 & 0.7 & 0.7 & 0.7 & 0.7 & 0.7 & 0.7 & 0.6 & 0.6 & 0.6 & 0.7 & 0.7 & 0.7 & 0.7 & 0.7 & 0.7 \\
\hline & 0.745 & 30 & 41 & 57 & 72 & 81 & 84 & 36 & 43 & 51 & 59 & 64 & 65 & 84 & 55 & 12 & 67 & 35 & 22 & 27 & 41 & 59 & 76 & 88 & 92 \\
\hline \multirow[b]{2}{*}{ SA } & & 0.6 & 0.7 & 0.7 & 0.8 & 0.8 & 0.8 & 0.7 & 0.7 & 0.7 & 0.7 & 0.6 & 0.6 & 0.7 & 0.7 & 0.6 & 0.6 & 0.5 & 0.5 & 0.7 & 0.7 & 0.7 & 0.7 & 0.7 & 0.7 \\
\hline & 0.723 & 71 & 10 & 66 & 19 & 53 & 66 & 36 & 26 & 13 & 00 & 90 & 86 & 75 & 36 & 78 & 18 & 78 & 61 & 08 & 20 & 34 & 48 & 57 & 60 \\
\hline \multirow[b]{2}{*}{ SO } & & 0.4 & 0.5 & 0.5 & 0.5 & 0.6 & 0.6 & 0.5 & 0.5 & 0.5 & 0.5 & 0.5 & 0.5 & 0.5 & 0.5 & 0.4 & 0.4 & 0.4 & 0.4 & 0.5 & 0.5 & 0.5 & 0.5 & 0.5 & 0.5 \\
\hline & 0.523 & 95 & 16 & 48 & 82 & 05 & 13 & 18 & 22 & 28 & 33 & 37 & 39 & 59 & 32 & 94 & 54 & 26 & 16 & 22 & 23 & 25 & 27 & 28 & 29 \\
\hline
\end{tabular}


As some organizations give more emphasis to 'DQ' while others consider 'IN' or 'CO' or 'FL' more important, the weight of a competitive priority primarily depends on the considered organization and its business strategy. Therefore, the above-detailed analysis (i.e., changing weights of competitive priority on a scale of 0 to 1 (with an interval of 0.2 )) presents a well-structured way to handle such situations and elucidates the following findings.

\subsection{Variations in the Weight of 'Delivery of Quality Services' (DQ)}

Figure 5 delineates the effect of variations in the weight of DQ on the CPS value of six dimensions of SFT. As the weight of DQ increases, the CPS value of 'EM', 'SA', and 'SO' significantly increases, while the CPS value of 'EN' significantly reduces. Alternatively, the CPS value of 'EC' and 'EF' slightly varies (i.e., 'EC' slightly decreases and 'EF' slightly increases) with an increase in the weight of DQ. The outcomes of this analysis reveal that organizations, whose business strategy is to give more weightage to DQ as compared to the other three competitive priorities, will eventually have 'SA' and 'EM' as the two most important dimensions of SFT with higher CPS and 'EN' with the least CPS value.

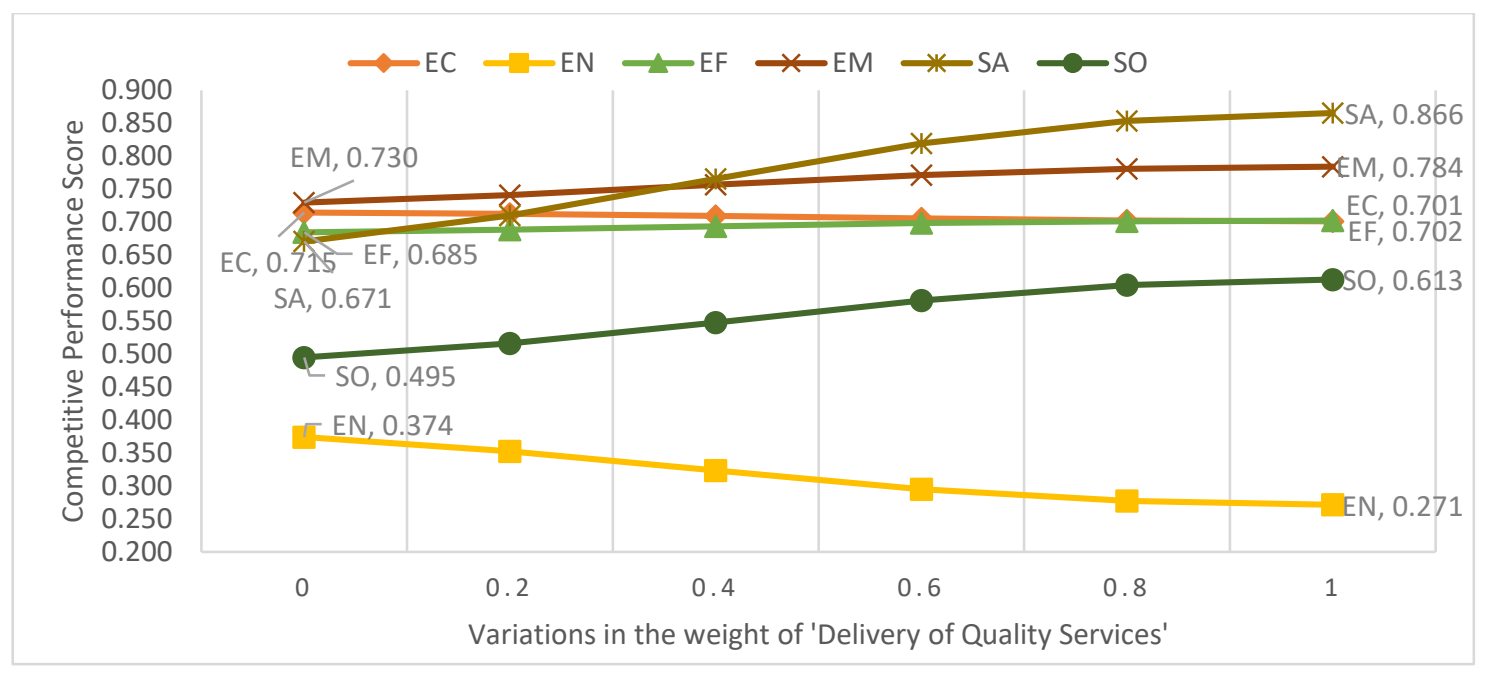

Figure 5 Variations in the Weight of DQ

\subsection{Variations in the Weight of 'Innovation' (IN)}

Figure 6 delineates the effect of variations in the weight of IN on the CPS value of six dimensions of SFT. As the weight of IN increases, the CPS value of 'EN', 'EF', and 'EM' significantly increases, while the CPS value of 'EC' and 'SA' significantly reduces. On the other hand, the CPS value of 'SO' slightly increases with an increase in the weight of IN. The outcomes of this analysis reveal that organizations, whose business strategy is to give more weightage to IN as compared to the other three 
competitive priorities, will eventually have 'EM' and 'EF' as the two most important dimensions of SFT with higher CPS and 'SO' with the least CPS value.

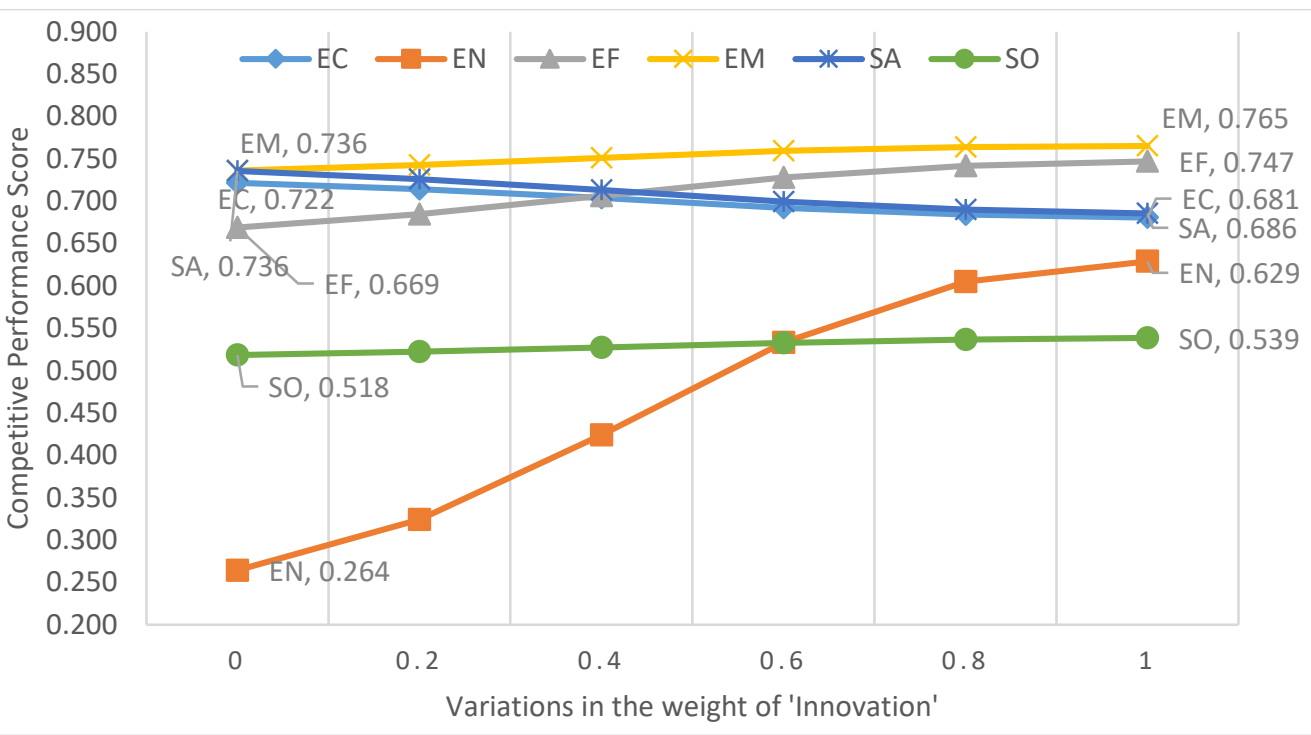

Figure 6 Variations in the Weight of Innovation

\subsection{Variations in the Weight of 'Cost' $(\mathrm{CO})$}

Figure 7 delineates the effect of variations in the weight of cost on the CPS value of six dimensions of SFT. As the weight of 'cost' rises, the CPS value of 'EC' significantly increases, while the CPS value of 'EM', 'EF', 'SA', 'SO', and 'EN' significantly reduces. The outcomes of this analysis reveal that organizations, whose business strategy is to give more weightage to cost as compared to the other three competitive priorities, will eventually have 'EC' and 'EM' as the two most important dimensions of SFT with higher CPS and 'EN' with the least CPS value.

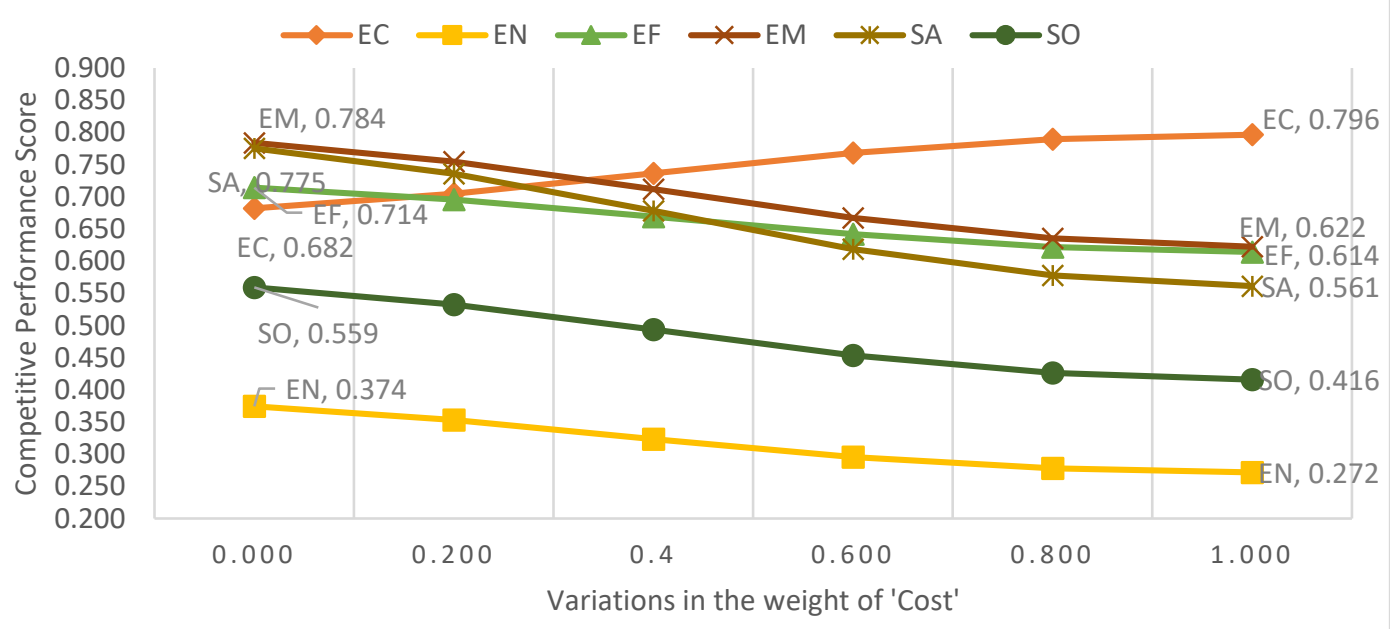


Figure 7 Variations in the Weight of Cost

\subsection{Variations in the Weight of 'Flexibility' (FL)}

Figure 8 delineates the effect of variations in the weight of flexibility on the CPS value of six dimensions of SFT. As the weight of 'flexibility' increases, the CPS value of 'EM' and 'SA' significantly increases, while the CPS value of 'EC' and 'EN' significantly reduces. On the other hand, the CPS value of 'EF' and 'SO' slightly varies (i.e., 'EF' slightly decreases and 'SO' slightly increases) with an increase in the weight of flexibility. The outcomes of this analysis reveal that organizations, whose business strategy is to give more weightage to flexibility as compared to the other three competitive priorities, will eventually have 'EM' and 'SA' as the two most important dimensions of SFT with higher CPS and 'EN' with the least CPS value.

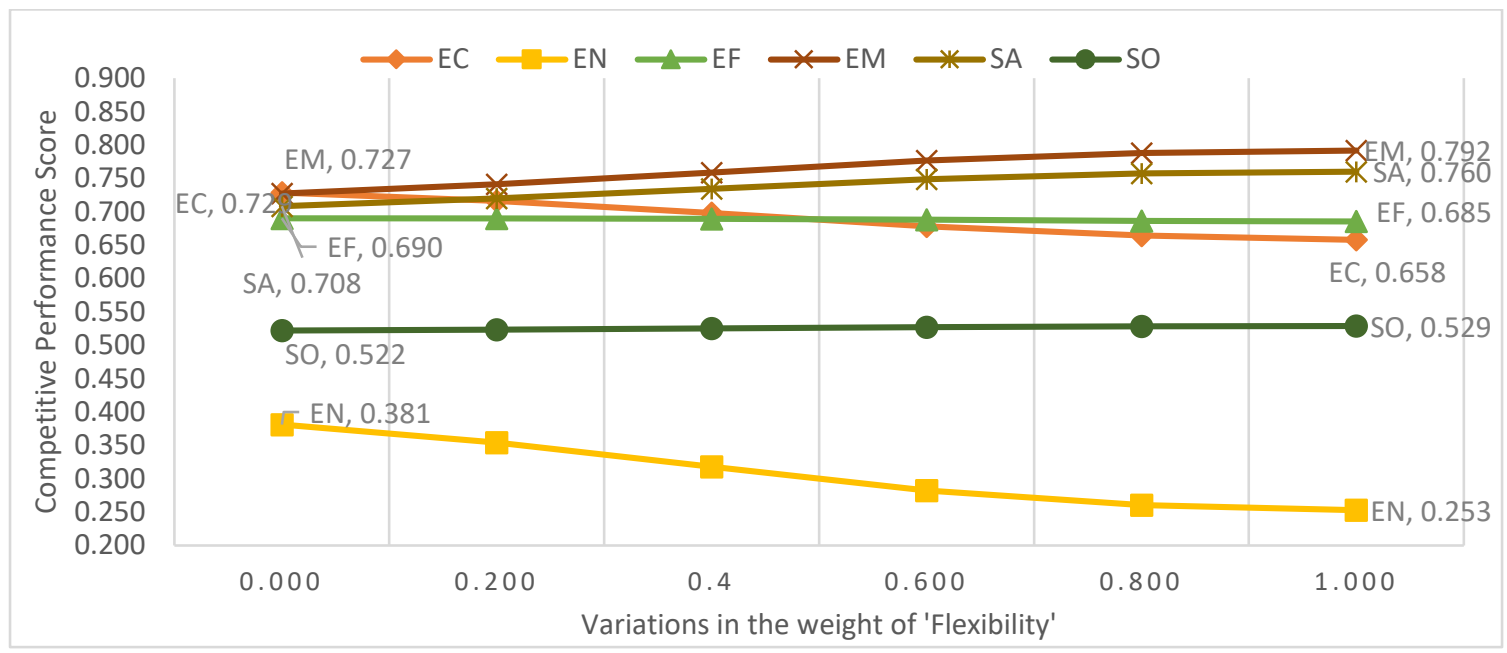

Figure 8 Variations in the Weight of Flexibility

\section{$7 \quad$ RESULTS AND DISCUSSION}

This research aims to assess the sustainability performance of freight transportation systems on the basis of competitive priorities. The outcomes of this study reveal that 'employing advanced technology dimension' (EM) is the most significant sustainability dimension with the highest competitive performance score (CPS) value. 'Safety dimension' (SA) and 'economic dimension' (EC) attain the second and third positions, respectively. Earlier studies have also signified that the implementation of advanced technologies (e.g., ITS, EDI) facilitates in enhancing the sustainability performance of FT (Mondragon et al., 2017; Shankar et al., 2019; Zhao et al., 2020). The four most significant CSFs influencing the competitive performance of SFT are 'intelligent transportation system (ITS)' (EM-4), 
'personnel training' (EC-2), 'adoption of safety standards' (SA-5), and 'efficient transport operations' (EF-4). Their CPS value is $0.833,0.829,0.806$, and 0.791 , respectively.

The outcomes of this study reveal (as depicted in Table 9) that none of the CSFs come under the category of 'not significant at all'. Therefore, all the identified CSFs of SFT are essential while assessing the overall competitive performance of an SFT system. As depicted in Figure 3, it is evident that eight CSFs (represented by blue color) are significant that achieve higher CPS value. These CSFs in the descending order of their CPS value are as follows: 'intelligent transportation system' (EM-4), 'personnel training' (EC-2), 'adoption of safety standards' (SA-5), 'efficient transport operations' (EF-4), 'operating cost' (EC-1), 'top management support for ICT usage' (EM-5), 'quality management' (EF-2), and 'cargo security' (SA-3). As six CSFs out of eight significant CSFs are from the three emerging sustainability factors (i.e., EM, EF, and SA), this finding ascertains the significance of three emerging sustainability dimensions in achieving higher competitive performance by a freight transport system. This outcome also corroborates an earlier study (Pathak et al., 2019), which brings out the significance of these three emerging sustainability factors in the performance assessment of SFT systems.

The next 18 CSFS (represented by yellow color) are of a moderately significant category that also requires attention for achieving a higher competitive advantage. These CSFs include 'SA-4', 'EF-6', 'EM-3', 'EC-5', ‘SO-5', 'EC-4', 'EM-2', 'SA-1', 'EM-1', 'EF-1', ‘SO-4', 'EF-5', ‘SA-2', 'EF-3', 'SO1', 'EN-7', 'EC-3', and 'SO-6' in the descending order of their CPS value. The remaining eight CSFs (represented by green color), i.e., 'SO-3', 'EN-4', 'EN-1', 'EN-3', 'SO-2', 'EN-5', 'EN-2', and 'EN-6' are categorized as slightly significant due to their lower CPS value.

The outcomes of sensitivity analysis reveal that the utilization of axioms assists in pinpointing the key sustainability CSFs that significantly affect the competitive performance of a freight operator (i.e., LSPs, carriers) and to enhance its robustness in the hypercompetitive marketplace. As all three axioms of sensitivity analysis are completely satisfied (John et al., 2014; Wan et al., 2019; Yang et al., 2009), it exhibits the robustness of the developed FERA-based performance assessment framework for SFT systems based on competitive priorities. Figure 4 graphically represents the results of sensitivity analysis for all CSFs and it is outlined in such a way that the variation (i.e., the difference between original CPS value and CPS value when aggregated normalized belief degree is reduced by 30\%) decreases while moving from left hand side to the right hand side (i.e., from 'accident rate' (SA-1) to 'visual intrusion' (EN-6)). Therefore, it is clear from Figure 4 that the maximum variations occur in the CPS value of 'accident rate' (SA-1), 'drivers' efficiency' (EF-3), and 'injury severity level' (SA-2). It denotes that 
the proposed model is more sensitive to 'accident rate' (SA-1), 'drivers' efficiency' (EF-3), and 'injury severity level' (SA-2) than to the other CSFs. The outcome of the sensitivity analysis further confirms the significance of 'safety' and 'efficiency' sustainability dimensions in the freight transport sector for achieving better competitive performance. Wang (2019) brings out the significance of the safety dimension in assessing road transport sustainability. Furthermore, due to the higher sensitivity, 'complying with government regulations for green practices implementation' (EN-7), 'loading factor' (EC-3), 'drivers' healthcare' (SO-6), and 'traffic clogging' (SO-1) are the critical CSFs affecting the overall competitive performance.

While performing the changing weight analysis, in the base model (i.e., when all competitive priorities are given equal importance), 'employing advanced technology dimension' (EM) achieves the highest CPS, and 'environmental dimension' (EN) attains the lowest CPS (refer to Table 13). The outcomes of different weight allocation scenarios reveal that 'EM', 'SA', and 'EC' factors of sustainability achieve higher CPS value whereas 'EN' and 'SO' achieve lower CPS value. Therefore, we can deduce that these factors (i.e., 'EM', 'SA', and 'EC') and their respective CSFs are the key elements that lead to attain higher competitive advantage. The top management should focus on these CSFs on a higher priority basis to remain competitive in the hypercompetitive market place. These findings, along with the outcomes of sensitivity analysis, depict the robustness of the developed model and signify that the variations in the weight of competitive priorities will not invalidate the findings of the developed framework. In sum, this research contributes to the literature on SFT as the existing studies significantly lack to analyze the sustainability performance of freight transport based on competitive priorities (Galeazzo and Klassen, 2015; Lin and Tseng, 2016). The exploration of the interaction between sustainability performance and competitive priorities has significant implications for logistics professionals in decision-making as well as performance management literature (e.g., Laari et al., 2018).

\section{CONCLUSION AND SCOPE FOR FUTURE WORK}

This study proposes a comprehensive performance assessment framework (PAF) based on competitive priorities for SFT systems by utilizing an integrated approach consisting of fuzzy group decisionmaking (FGDM), fuzzy evidential reasoning algorithm (FERA), and expected utility theory. As discussed, FERA utilizes the concepts of FST and ERA. This framework assesses the identified (i.e., 34) CSFs that influence the performance of SFT based on competitive priorities. These CSFs are categorized into six sustainability dimensions (i.e., 'economic' (EC), 'environmental' (EN), 'employing advanced technology' (EM), 'efficiency' (EF), 'safety' (SA), and 'social' (SO)). Further, 
'delivery of quality services' (DQ), 'innovation' (IN), 'cost' (CO), and 'flexibility' (FL) are considered as the key competitive priorities for the transportation sector. This study also demonstrates the use of an improved and efficient methodology proposed by Chen (1998) for aggregation of fuzzy opinions. A case example of the FT sector in India is considered to exhibit the appositeness of the developed framework. The proposed competitive performance score (CPS) based PAF for SFT systems assists in managing the uncertainties involved in the decision-making. Eventually, this research also analyzes the effect of variations in the weight of each competitive priorities on the CPS value of six dimensions of SFT. The proposed model is a significant step forward for an organization to emphasize sustainability factors for improving its competitive performance.

This study has significant implications for both logistics professionals and researchers. The outcomes of the proposed model highlight the importance of each sustainability CSF in attaining better competitive performance by freight operators. This study highlights the four key competitive priorities of the transport sector (i.e., 'DQ', 'IN', 'CO', and 'FL') and signifies the importance of sustainability as well as competitive priorities while assessing the performance of an FT system. Presently, this knowledge has become essential for logistics professionals and decision-makers to develop the required strategies that encompass sustainability and will lead to improving the competitive performance of an FT system. This study also apprises logistics professionals about the key sustainability dimensions (i.e., 'EM', 'SA', and 'EC') that lead to attain higher competitive advantage under different weight allocation scenarios.

The novelty of this research lies in developing a framework for sustainability performance assessment based on competitive priorities under uncertainties, identifying key CSFs that are crucial to improve competitive performance, and proposing a CPS-based PAF for SFT systems. The CPS value acts as an objective tool for evaluating the competitive performance of an SFT system. This CPS-based PAF facilitates logistics professionals to pinpoint the most and least significant CSFs that affect the overall competitive performance. Furthermore, the methodological facets elucidated in this research have significant insinuations for researchers as well as practitioners. There are some limitations of the proposed framework. First, this research develops a comprehensive PAF to assess the sustainability performance of freight operators (i.e., LSPs and carriers) involved in rail-based and road-based multimodal FT. Second, the findings of this research cannot be directly utilized for temperature-controlled transportation that includes the shipping of perishable goods. Moreover, as the transport sector faces environmental regulations that vary from one country to another, the generalization of the findings to 
the logistics sector in other countries very different from India should be undertaken with caution. As scope for future research, the impact of considering more experts on the aggregated outcomes can be examined. Future studies may perform this analysis for an individual freight operator, and its overall sustainability CPS value can be calculated by aggregating normalized belief degrees for six dimensions of sustainability. In this research, we have consulted experts associated with the Indian transport and logistics sector. Future research can be done for developed countries, and a comparison analysis can also be performed. The obtained results and suggested methodology can be further extended and adapted by the top management of an organization according to its specific characteristics.

\section{ACKNOWLEDGMENTS:}

The authors are indebted to the anonymous referees for their constructive feedbacks which significantly helped to improving the paper.

\section{REFERENCES}

Abbasi, M., Nilsson, F., 2016. Developing environmentally sustainable logistics. Exploring themes and challenges from a logistics service providers' perspective. Transp. Res. Part D Transp. Environ. 46, 273283. https://doi.org/10.1016/j.trd.2016.04.004

Akhoundi, A., Nazif, S., 2018. Sustainability assessment of wastewater reuse alternatives using the evidential reasoning approach. J. Clean. Prod. 195, 1350-1376. https://doi.org/10.1016/j.jclepro.2018.05.220

Ansari, Z.N., Kant, R., 2017. Exploring the framework development status for sustainability in supply chain management: A systematic literature synthesis and future research directions. Bus. Strateg. Environ. 26(7), 873-892.

Awasthi, A., Chauhan, S.S., 2012. A hybrid approach integrating Affinity Diagram, AHP and fuzzy TOPSIS for sustainable city logistics planning. Appl. Math. Model. 36, 573-584. https://doi.org/10.1016/j.apm.2011.07.033

Awasthi, A., Chauhan, S.S., 2011. Using AHP and Dempster-Shafer theory for evaluating sustainable transport solutions. Environ. Model. Softw. 26, 787-796. https://doi.org/10.1016/j.envsoft.2010.11.010

Ayati, E., Neghab, M. ali P., Sadeghi, A. asghar, Moghaddam, A.M., 2012. Introducing roadside hazard severity indicator based on evidential reasoning approach. Saf. Sci. 50, 1618-1626. https://doi.org/10.1016/j.ssci.2012.03.023

Bandeira, R.A. de M., Goes, G.V., Gonçalves, D.N.S., D’Agosto, M. de A., Oliveira, C.M. de, 2019. Electric vehicles in the last mile of urban freight transportation: A sustainability assessment of postal deliveries in Rio de Janeiro- Brazil. Transp. Res. Part D 67, 491-502. https://doi.org/10.1016/j.trd.2018.12.017

Bandeira, R.A.M., D’Agosto, M.A., Ribeiro, S.K., Bandeira, A.P.F., Goes, G. V., 2018. A fuzzy multi-criteria model for evaluating sustainable urban freight transportation operations. J. Clean. Prod. 184, 727-739. https://doi.org/10.1016/j.jclepro.2018.02.234

Behrends, S., 2011. Urban freight transport sustainability. Framework. Chalmers University of Technology, Gothenburg, Sweden. https://doi.org/10.1007/s100520050195

Bektas, T., Ehmke, J.F., Psaraftis, H.N., Puchinger, J., 2019. The role of operational research in green freight transportation. Eur. J. Oper. Res. 274, 807-823.

Blinge, M., 2014. Policy measures to realise green corridors - A stakeholder perspective. Res. Transp. Bus. Manag. 12, 55-62. https://doi.org/10.1016/j.rtbm.2014.06.007

Bouranta, N., Psomas, E., 2017. A comparative analysis of competitive priorities and business performance between manufacturing and service firms. Int. J. Product. Perform. Manag. 66, 914-931. 
Cao, X., Siu, J., Lam, L., 2019. A fast reaction-based port vulnerability assessment: Case of Tianjin Port explosion. Transp. Res. Part A Policy Pract. 128, 11-33. https://doi.org/10.1016/j.tra.2019.05.019

Castillo, H., Pitfield, D.E., 2010. ELASTIC - A methodological framework for identifying and selecting sustainable transport indicators. Transp. Res. Part D Transp. Environ. 15, 179-188. https://doi.org/10.1016/j.trd.2009.09.002

Centobelli, P., Cerchione, R., Esposito, E., 2017. Environmental sustainability in the service industry of transportation and logistics service providers: Systematic literature review and research directions. Transp. Res. Part D Transp. Environ. 53, 454-470. https://doi.org/10.1016/j.trd.2017.04.032

Chen, S.-M., 1998. Aggregating fuzzy opinions in the group decision-making environment. Cybern. Syst. 29, 363-376. https://doi.org/10.1080/01969720590908294

Corbo, R., Glaus, M., 2019. Design of material transportation systems for sustainability. Transp. Res. Part D Transp. Environ. 75, 13-22. https://doi.org/10.1016/j.trd.2019.08.014

Craig, A.J., Blanco, E.E., Sheffi, Y., 2013. Estimating the CO2 intensity of intermodal freight transportation. Transp. Res. Part D Transp. Environ. 22, 49-53. https://doi.org/10.1016/j.trd.2013.02.016

Crainic, T.G., Laporte, G., 1997. Planning models for freight transportation. Eur. J. Oper. Res. 97, 409-438. https://doi.org/10.1016/S0377-2217(96)00298-6

Dangayach, G.S., Deshmukh, S.G., 2006. An exploratory study of manufacturing strategy practices of machinery manufacturing companies in India. Omega 34, 254-273. https://doi.org/10.1016/j.omega.2004.10.009

Demir, E., Huang, Y., Scholts, S., Woensel, T. Van, 2015. A selected review on the negative externalities of the freight transportation: Modeling and pricing. Transp. Res. Part E Logist. Transp. Rev. 77, 95-114. https://doi.org/10.1016/j.tre.2015.02.020

Ellram, L.M., Murfield, M.L.U., 2017. Environmental sustainability in freight transportation: A systematic literature review and agenda for future research. Transp. J. 56, 263-298.

ERTRAC, 2011. Sustainable Freight System for Europe Green, Safe and Efficient Corridors. ERTRAC Research and Innovation Roadmaps. Available at: http://www.ertrac.org/uploads/documents_publications/Roadmap/Sustainable\%20Freight\%20Sy stem\%20for\%20Europe\%20-\%20Green,\%20Safe\%20and\%20Efficient\%20Corridors.pdf. (accessed on 24 October 2019).

Galeazzo, A., Klassen, R.D., 2015. Organizational context and the implementation of environmental and social practices: What are the linkages to manufacturing strategy? J. Clean. Prod. 108, 158-168. https://doi.org/10.1016/j.jclepro.2015.06.053

Gholami, A., Ziaee, M., 2017. Development of a performance measurement system to choose the most efficient programs, the case of the Mashhad transportation system. Transp. Res. Part A 106, 261-277.

Godaliyadde, D., Godaliyadde, L.B., Phylip-Jones, G., Yang, Z.L., Batako, A.D., Wang, J., 2010. A Subjective Multiple Criteria Decision-Making Approach for Modeling Ship Hull Vibration. Mar. Technol. Soc. J. 44(5), 25-42.

Govindan, K., Seuring, S., Zhu, Q., Garrido, S., 2016. Accelerating the transition towards sustainability dynamics into supply chain relationship management and governance structures. J. Clean. Prod. 112, 1813-1823. https://doi.org/10.1016/j.jclepro.2015.11.084

Havenga, J.H., Simpson, Z.P., 2018. Freight logistics' contribution to sustainability: Systemic measurement facilitates behavioural change. Transp. Res. Part D Transp. Environ. 58, 320-331. https://doi.org/10.1016/j.trd.2016.08.035

Hayes, R.H., Wheelwright, S.C., 1984. Restoring our competitive edge: competing through manufacturing. New York, NY: John Wiley \& Sons.

He, Z., Chen, P., Liu, H., Guo, Z., 2017. Performance measurement system and strategies for developing lowcarbon logistics: A case study in China. J. Clean. Prod. 156, 395-405. https://doi.org/10.1016/j.jclepro.2017.04.071

Hsu, H.-M., Chen, C.-T., 1996. Aggregation of fuzzy opinions under group decision making. Fuzzy Sets Syst. 79, 279-285. https://doi.org/10.1016/0165-0114(95)00185-9

Hunke, K., Prause, G., 2013. Management of green corridor performance. Transp. Telecommun. 14, 292-299. https://doi.org/10.2478/ttj-2013-0025

Idris, F., Naqshbandi, M.M., 2019. Exploring competitive priorities in the service sector: evidence from India. 
$\begin{array}{llllll}\text { Int. J. Qual. Serv. Sci. 11(2), } & \text { 167-186. https://doi.org/10.1108/IJQSS-02-2018-0021 } \\ \text { IEA, } & 2018 . & \mathrm{CO}_{2} & \text { emissions from } & \text { fuel combustion. } & \text { Available at: }\end{array}$ http://www.indiaenvironmentportal.org.in/files/file/CO2_Emissions_from_Fuel_Combustion_2018_Highl ights.pdf. (accessed on 24 October 2019)

Jakhar, S.K., 2015. Performance evaluation and a flow allocation decision model for a sustainable supply chain of an apparel industry. J. Clean. Prod. 87, 391-413. https://doi.org/10.1016/j.jclepro.2014.09.089

Janjevic, M., Knoppen, D., Winkenbach, M., 2019. Integrated decision-making framework for urban freight logistics policy-making. Transp. Res. Part D Transp. Environ. 72, 333-357. https://doi.org/10.1016/j.trd.2019.05.006

Jeon, C.M., Amekudzi, A., 2005. Addressing Sustainability in Transportation Systems: Definitions, Indicators, and Metrics. J. Infrastruct. Syst. 11, 31-50. https://doi.org/10.1061/(ASCE)1076-0342(2005)11:1(31)

Jeon, C.M., Amekudzi, A.A., Guensler, R.L., 2013. Sustainability assessment at the transportation planning level: Performance measures and indexes. Transp. Policy 25, 10-21. https://doi.org/10.1016/j.tranpol.2012.10.004

Jeon, C.M., Amekudzi, A.A., Guensler, R.L., 2010. Evaluating Plan Alternatives for Transportation System Sustainability: Atlanta Metropolitan Region. Int. J. Sustain. Transp. 4, 227-247. https://doi.org/10.1080/15568310902940209

John, A., Paraskevadakis, D., Bury, A., Yang, Z., Riahi, R., Wang, J., 2014. An integrated fuzzy risk assessment for seaport operations. Saf. Sci. 68, 180-194. https://doi.org/10.1016/j.ssci.2014.04.001

Kathuria, R., Anandarajan, M., Igbaria, M., 1999. Selecting IT applications in manufacturing: a KBS approach. Omega 27, 605-616.

Khorheh, M.A., Moisiadis, F., Davarzani, H., 2015. Socio-environmental performance of transportation systems. Manag. Environ. Qual. An Int. J. 26, 826-851. https://doi.org/10.1108/MEQ-09-2014-0140

Kroes, J.R., Ghosh, S., 2010. Outsourcing congruence with competitive priorities: Impact on supply chain and firm performance. J. Oper. Manag. 28, 124-143. https://doi.org/10.1016/j.jom.2009.09.004

Kumar, A., Anbanandam, R., 2019. Development of Social Sustainability Index for Freight Transportation System. J. Clean. Prod. 210, 77-92. https://doi.org/10.1016/j.jclepro.2018.10.353

Kumar, A., Anbanandam, R., 2020. Assessment of environmental and social sustainability performance of the freight transportation industry: An index-based approach. Transp. Policy. https://doi.org/10.1016/j.tranpol.2020.01.006

Laari, S., Töyli, J., Ojala, L., 2018. The effect of a competitive strategy and green supply chain management on the financial and environmental performance of logistics service providers. Bus. Strateg. Environ. 27, 872883. https://doi.org/10.1002/bse.2038

Lai, K. hung, Ngai, E.W.T., Cheng, T.C.E., 2002. Measures for evaluating supply chain performance in transport logistics. Transp. Res. Part E Logist. Transp. Rev. 38, 439-456. https://doi.org/10.1016/S13665545(02)00019-4

Lai, L., 2008. An evaluation of fuzzy transportation underwriting systematic risk. Transp. Res. Part A Policy Pract. 42, 1231-1237. https://doi.org/10.1016/j.tra.2008.03.010

Léonardi, J., Baumgartner, M., 2004. CO2efficiency in road freight transportation: Status quo, measures and potential. Transp. Res. Part D Transp. Environ. 9, 451-464.

Li, L., Zhang, X., 2020. Reducing CO2 emissions through pricing, planning, and subsidizing rail freight. Transp. Res. Part D Transp. Environ. 87, 102483. https://doi.org/10.1016/j.trd.2020.102483

Li, S., Ragu-nathan, B., Ragu-nathan, T.S., Rao, S.S., 2006. The impact of supply chain management practices on competitive advantage and organizational performance. Omega 34, 107-124. https://doi.org/10.1016/j.omega.2004.08.002

Li, X., Li, F., Zhao, N., Zhu, Q., 2018. Measuring environmental sustainability performance of freight transportation seaports in China: A data envelopment analysis approach based on the closest targets. Expert Syst. 1-12. https://doi.org/10.1111/exsy.12334

Liljestrand, K., 2016. Improvement actions for reducing transport's impact on climate: A shipper's perspective. Transp. Res. Part D Transp. Environ. 48, 393-407. https://doi.org/10.1016/j.trd.2016.08.021

Lin, Y.H., Tseng, M.L., 2016. Assessing the competitive priorities within sustainable supply chain management under uncertainty. J. Clean. Prod. 112, 2133-2144. https://doi.org/10.1016/j.jclepro.2014.07.012

Litman, T., 2007. Developing indicators for comprehensive and sustainable transport planning. Trans. Res. Rec. 
2017(1), 10-15.

Liu, C.L., Lyons, A.C., 2011. An analysis of third-party logistics performance and service provision. Transp. Res. Part E Logist. Transp. Rev. 47, 547-570. https://doi.org/10.1016/j.tre.2010.11.012

Magon, R.B., Thomé, A.M.T., Ferrer, A.L.C., Scavarda, L.F., 2018. Sustainability and performance in operations management research. J. Clean. Prod. 190, 104-117. https://doi.org/10.1016/j.jclepro.2018.04.140

Miller, P., de Barros, A.G., Kattan, L., Wirasinghe, S.C., 2016. Analyzing the sustainability performance of public transit. Transp. Res. Part D Transp. Environ. 44, 177-198. https://doi.org/10.1016/j.trd.2016.02.012

Mondragon, A.E.C., Mondragon, C.E.C., Coronado, E.S., 2017. ICT adoption in multimodal transport sites: Investigating institutional-related influences in international seaports terminals. Transp. Res. Part A Policy Pract. 97, 69-88. https://doi.org/10.1016/j.tra.2017.01.014

Novonous Report, 2015. Freight Transport Market in India 2015-2020. Available at: http://www.novonous.com/publications/freight-transport-market-india-2015-2020. (accessed on 02 November 2019)

Olhager, J., Prajogo, D.I., 2012. The impact of manufacturing and supply chain improvement initiatives: A survey comparing make-to-order and make-to-stock firms. Omega 40, 159-165. https://doi.org/10.1016/j.omega.2011.05.001

Panagakos, G., 2016. Green Corridors Basics, in: Psaraftis, H.N. (Ed.), Green Transportation Logistics: The Quest for Win-Win Solutions. pp. 81-121. https://doi.org/10.1007/978-3-319-17175-3

Panagakos, G., Psaraftis, H.N., 2017. Model-based corridor performance analysis - An application to a European case. Eur. J. Transp. Infrastruct. Res. 17, 225-247. https://doi.org/10.18757/ejtir.2017.17.2.3192

Parikh, K., 2012. Sustainable development and low carbon growth strategy for India. Energy 40, 31-38. https://doi.org/10.1016/j.energy.2012.01.013

Pathak, D.K., Thakur, L.S., Rahman, S., 2019. Performance evaluation framework for sustainable freight transportation systems. Int. J. Prod. Res. 57(19), 6202-6222. https://doi.org/10.1080/00207543.2019.1602741

Perego, A., Perotti, S., Mangiaracina, R., 2011. ICT for logistics and freight transportation: A literature review and research agenda. Int. J. Phys. Distrib. Logist. Manag. 41, 457-483. https://doi.org/10.1108/09600031111138826

Phusavat, K., Kanchana, R., 2008. Competitive priorities for service providers: perspectives from Thailand. Ind. Manag. Data Syst. 108, 5-21. https://doi.org/10.1108/02635570810844052

Piecyk, M.I., McKinnon, A.C., 2010. Forecasting the carbon footprint of road freight transport in 2020. Int. J. Prod. Econ. 128, 31-42. https://doi.org/10.1016/j.ijpe.2009.08.027

Prajogo, D.I., Mcdermott, P., 2011. Examining competitive priorities and competitive advantage in service organisations using Importance-Performance Analysis matrix. Manag. Serv. Qual. An Int. J. 21, 465-483. https://doi.org/10.1108/09604521111159780

Prause, G., 2014. A green corridor balanced scorecard. Transp. Telecommun. 15, $299-307$. https://doi.org/10.2478/ttj-2014-0026

Prause, G., Schröder, M., 2015. KPI building blocks for successful green transport corridor implementation. Transp. Telecommun. 16, 277-287. https://doi.org/10.1515/ttj-2015-0025

Qin, J., Xi, Y., Pedrycz, W., 2020. Failure mode and effects analysis (FMEA) for risk assessment based on interval type-2 fuzzy evidential reasoning method. Appl. Soft Comput. J. 89, 106134. https://doi.org/10.1016/j.asoc.2020.106134

Rai, H.B., Lier, T. Van, Meers, D., Macharis, C., 2017. Improving urban freight transport sustainability: Policy assessment framework and case study. Res. Transp. Econ. 64, 26-35. https://doi.org/10.1016/j.retrec.2017.08.005

Rajak, S., Parthiban, P., Dhanalakshmi, R., 2016. Sustainable transportation systems performance evaluation using fuzzy logic. Ecol. Indic. 71, 503-513. https://doi.org/10.1016/j.ecolind.2016.07.031

Ramani, T.L., Zietsman, J., Knowles, W.E., Quadrifoglio, L., 2011. Sustainability Enhancement Tool for State Departments of Transportation Using Performance Measurement. J. Transp. Eng. 137, 404-415. https://doi.org/10.1061/(ASCE)TE.1943-5436.0000255

Ratanavaraha, V., Jomnonkwao, S., 2015. Trends in Thailand $\mathrm{CO}_{2}$ emissions in the transportation sector and Policy Mitigation. Transp. Policy 41, 136-146. https://doi.org/10.1016/j.tranpol.2015.01.007 
Reefke, H., Sundaram, D., 2017. Key themes and research opportunities in sustainable supply chain management - identification and evaluation. Omega 66, 195-211. https://doi.org/10.1016/j.omega.2016.02.003

Reisi, M., Aye, L., Rajabifard, A., Ngo, T., 2014. Transport sustainability index: Melbourne case study. Ecol. Indic. 43, 288-296. https://doi.org/10.1016/j.ecolind.2014.03.004

Richardson, B.C., 2005. Sustainable transport: Analysis frameworks. J. Transp. Geogr. 13, $29-39$. https://doi.org/10.1016/j.jtrangeo.2004.11.005

Rockart, J.F., 1979. Chief executives define their own data needs. Harvard Bus. Rev. 57(2), 81-93.

Roth, A., Kåberger, T., 2002. Making transport systems sustainable. J. Clean. Prod. 10, 361-371.

Santos, A.S., Ribeiro, S.K., 2013. The use of sustainability indicators in urban passenger transport during the decision-making process: The case of Rio de Janeiro, Brazil. Curr. Opin. Environ. Sustain. 5, 251-260.

Shankar, R., Pathak, D.K., Choudhary, D., 2019. Decarbonizing freight transportation: An integrated EFA-TISM approach to model enablers of dedicated freight corridors. Technol. Forecast. Soc. Chang. 143, 85-100. https://doi.org/10.1016/j.techfore.2019.03.010

Shiau, T.A., Chuang, Y.R., 2012. Evaluating gravel transport sustainability: A case study of Taiwan's northeast corridor. Transp. Res. Part D Transp. Environ. 17, 287-292. https://doi.org/10.1016/j.trd.2012.01.003

Shiau, T.A., Huang, M.W., Lin, W.Y., 2015. Developing an Indicator System for Measuring Taiwan's Transport Sustainability. Int. J. Sustain. Transp. 9, 81-92. https://doi.org/10.1080/15568318.2012.738775

Solomon, A., Ketikidis, P., Koh, S.C.L., 2019. Including social performance as a measure for resilient and green freight transportation. Transp. Res. Part D 69, 13-23. https://doi.org/10.1016/j.trd.2019.01.023

Statistics Times, 2019. Sector wise GDP of India. Available at: http://statisticstimes.com/economy/sectorwisegdp-contribution-of-india.php (accessed on 26 October 2019)

Stefaniec, A., Hosseini, K., Xie, J., Li, Y., 2020. Sustainability assessment of inland transportation in China: A triple bottom line-based network DEA approach. Transp. Res. Part D Transp. Environ. 80, 102258. https://doi.org/10.1016/j.trd.2020.102258

Stephenson, J., Spector, S., Hopkins, D., McCarthy, A., 2018. Deep interventions for a sustainable transport future. Transp. Res. Part D Transp. Environ. 61, 356-372. https://doi.org/10.1016/j.trd.2017.06.031

Taniguchi, E., Imanishi, Y., Barber, R., James, J., Debauche, W., 2014. Public Sector Governance to Implement Freight Vehicle Transport Management. Procedia - Soc. Behav. Sci. 125, 345-357. https://doi.org/10.1016/j.sbspro.2014.01.1479

Tob-Ogu, A., Kumar, N., Cullen, J., 2018. ICT adoption in road freight transport in Nigeria - A case study of the petroleum downstream sector. Technol. Forecast. Soc. Change 131, 240-252.

Wan, C., Yan, X., Zhang, D., Yang, Z., 2019. A novel policy making aid model for the development of LNG fuelled ships. Transp. Res. Part A Policy Pract.119, 29-44. https://doi.org/10.1016/j.tra.2018.10.038

Wan, C., Zhang, D., Yan, X., Yang, Z., 2018. A novel model for the quantitative evaluation of green port development - A case study of major ports in China. Transp. Res. Part D Transp. Environ. 61, 431-443. https://doi.org/10.1016/j.trd.2017.06.021

Wang, D.D., 2019. Assessing road transport sustainability by combining environmental impacts and safety concerns. Transp. Res. Part D Transp. Environ. 77, 212-223. https://doi.org/10.1016/j.trd.2019.10.022

Yan, X., Zhang, D., Yang, Z., Zhang, J., Wang, J., 2015. Use of fuzzy rule-based evidential reasoning approach in the navigational risk assessment of inland waterway transportation systems. Saf. Sci. 82, 352-360. https://doi.org/10.1016/j.ssci.2015.10.004

Yang, J.-B., 2001. Rule and utility based evidential reasoning approach for multiattribute decision analysis under uncertainties. Eur. J. Oper. Res. 131, 31-61.

Yang, J.B., Wang, Y.M., Xu, D.L., Chin, K.S., 2006. The evidential reasoning approach for MADA under both probabilistic and fuzzy uncertainties. Eur. J. Oper. Res. 171, 309-343. https://doi.org/10.1016/j.ejor.2004.09.017

Yang, J.B., Xu, D.L., 1999. Intelligent decision system via evidential reasoning. IDSL, Cheshire, England.

Yang, J., Xu, D., 2002. On the Evidential Reasoning Algorithm for Multiple Attribute Decision Analysis Under Uncertainty. IEEE Trans. Syst. Man Cybern. Part A Syst. Humans 32, 289-304.

Yang, Z.L., Wang, J., Bonsall, S., Fang, Q.G., 2009. Use of fuzzy evidential reasoning in maritime security assessment. Risk Anal. 29, 95-120. https://doi.org/10.1111/j.1539-6924.2008.01158.x

Yeung, K., Zhou, H., Yeung, A.C.L., Cheng, T.C.E., 2012. The impact of third-party logistics providers' 
capabilities on exporters' performance. Int. J. Prod. Econ. 135, 741-753. https://doi.org/10.1016/j.ijpe.2011.10.007

Yoshimoto, R., Nemoto, T., 2005. The Impact of Information and Communication Technology on Road Freight Transportation. IATSS Res. 29, 16-21. https://doi.org/10.1016/S0386-1112(14)60114-X

Zadeh, L.A., 1965. Fuzzy sets. Inform. Control 8(3), 338-353.

Zhao, X., Ke, Y., Zuo, J., Xiong, W., Wu, P., 2020. Evaluation of sustainable transport research in 2000-2019. J. Clean. Prod. 256, 120404. https://doi.org/10.1016/j.jclepro.2020.120404

Zhou, M., Liu, X., Yang, J., Chen, Y., Wu, J., 2019. Evidential reasoning approach with multiple kinds of attributes and entropy-based weight assignment. Knowledge-Based Syst. 163, 358-375. https://doi.org/10.1016/j.knosys.2018.08.037

\section{Appendix-I}

\section{Sample Calculation representing Aggregation part of ERA}

We represent the computation for aggregation of belief degree for 'personnel training' (EC-2) on the basis of four competitive priorities (please refer to Table 7).

\begin{tabular}{|l|l|l|l|l|l|}
\hline & VL & L & M & H & VH \\
\hline DQ & 0.000 & 0.000 & 0.128 & 0.433 & 0.439 \\
\hline IN & 0.000 & 0.000 & 0.166 & 0.458 & 0.376 \\
\hline CO & 0.000 & 0.000 & 0.082 & 0.400 & 0.518 \\
\hline FL & 0.000 & 0.000 & 0.166 & 0.458 & 0.376 \\
\hline
\end{tabular}

As these four attributes are assigned equal weightage, from Equation (9) $\mathrm{L}=4$, and $\theta_{1}=\theta_{2}=\theta_{3}=\theta_{4}=0.25$. Basis probability mass and residual probability mass are computed by using Equation (13) and (14a).

\begin{tabular}{|l|l|l|l|l|l|l|l|}
\hline & \multicolumn{5}{|c|}{$p_{n, i}$} & \multicolumn{1}{c|}{$\bar{p}_{H, i}$} & $\tilde{p}_{H, i}$ \\
\hline DQ & 0 & 0 & 0.032 & 0.1083 & 0.1098 & 0.75 & 0 \\
\hline IN & 0 & 0 & 0.0415 & 0.1145 & 0.094 & 0.75 & 0 \\
\hline CO & 0 & 0 & 0.0205 & 0.10 & 0.1295 & 0.75 & 0 \\
\hline FL & 0 & 0 & 0.0415 & 0.1145 & 0.094 & 0.75 & 0 \\
\hline
\end{tabular}

Using Equations (15) - (17), we compute the combined probability masses as follows. First, we aggregate Delivery of quality services $(D Q)$ and Innovation $(I N)$.

$N F_{I 2}=[1-(0+\ldots+0+0.032 \times 0.1145+0.032 \times 0.094+0+0+0.1083 \times 0.094+0.1083 \times$ $0.0415+0+0+0.1098 \times 0.1145+0.1098 \times 0.0415]^{-1}=1.04$

And aggregated probability masses values are as follows

$p_{3, I 2}=1.04 \times[(0.032 \times 0.0415)+(0.0415 \times(0.75+0))+(0.032 \times(0.75+0))]=0.05871 \quad($ similarly, other values are calculated)

\begin{tabular}{|r|r|r|r|r|r|r|}
\hline \multicolumn{5}{|c|}{$p_{n, I 2}$} & $\bar{p}_{H, I 2}$ & $\tilde{p}_{H, I 2}$ \\
\hline 0 & 0 & 0.0587 & 0.1866 & 0.1697 & 0.585 & 0 \\
\hline
\end{tabular}

Now, we combine the above results for Delivery of quality services $(D Q)$ and Innovation $(I N)$ with $C o s t(C O) . N F_{I 3}=\mathbf{1 . 0 6 6}$

\begin{tabular}{|r|r|r|r|r|r|r|}
\hline \multicolumn{3}{|c|}{$p_{n, I 3}$} & $\bar{p}_{H, I 3}$ & $\tilde{p}_{H, I 3}$ \\
\hline 0 & 0 & 0.061 & 0.2315 & 0.2398 & 0.4677 & 0 \\
\hline
\end{tabular}

Now, we combine the above results for Delivery of quality services (DQ), Innovation (IN), and Cost (CO) with Flexibility $(F L)$.

$N F_{I 4}=\mathbf{1 . 0 8 8 7}$ 


\begin{tabular}{|r|r|r|r|r|r|r|}
\hline \multicolumn{9}{|c|}{$p_{n, I 4}$} & $\bar{p}_{H, I 4}$ & $\tilde{p}_{H, I 4}$ \\
\hline 0 & 0 & 0.0737 & 0.2762 & 0.2682 & 0.3819 & 0 \\
\hline
\end{tabular}

Further, by using Equations (18) and (19), aggregated normalized belief degrees of EC2 for all competitive priorities are computed as follows.

$\beta_{3}=\frac{0.0737}{1-0.3819}=0.119$ (similarly, other values are calculated)

\begin{tabular}{|r|r|r|r|r|r|}
\hline$\beta_{1}$ & $\beta_{2}$ & $\beta_{3}$ & $\beta_{4}$ & $\beta_{5}$ & $\beta_{H}$ \\
\hline 0 & 0 & 0.119 & 0.447 & 0.434 & 0 \\
\hline
\end{tabular}

These results are the same as reported in Table 9.

\section{Appendix-II}

\section{LIST OF ABBREVIATIONS}

\begin{tabular}{|c|c|}
\hline AHP & Analytical Hierarchy Process \\
\hline $\mathrm{CO}$ & Cost \\
\hline CPS & Competitive Performance Score \\
\hline CSF & Critical Success Factor \\
\hline CSI & Composite Sustainability Index \\
\hline DEA & Data Envelopment Analysis \\
\hline DQ & Delivery of Quality Services \\
\hline $\mathrm{EC}$ & Economic Dimension \\
\hline EDI & Electronic Data Interchange \\
\hline $\mathrm{EF}$ & Efficiency Dimension \\
\hline EM & Employing Advanced Technology Dimension \\
\hline EN & Environmental Dimension \\
\hline ERA & Evidential Reasoning Algorithm \\
\hline FAHP & Fuzzy Analytical Hierarchy Process \\
\hline FERA & Fuzzy Evidential Reasoning Algorithm \\
\hline FGDM & Fuzzy Group Decision Making \\
\hline FL & Flexibility \\
\hline FST & Fuzzy Set Theory \\
\hline FT & Freight Transportation \\
\hline GSCM & Green Supply Chain Management \\
\hline GTC & Green Transport Corridor \\
\hline ICT & Information and Communication Technology \\
\hline IDS & Intelligent Decision System \\
\hline IN & Innovation \\
\hline ITS & Intelligent Transportation System \\
\hline KPI & Key Performance Indicators \\
\hline LSP & Logistics Service Provider \\
\hline MCDM & Multi-criteria Decision Making \\
\hline PAF & Performance Assessment Framework \\
\hline PMS & Performance Measurement System \\
\hline SA & Safety Dimension \\
\hline SEM & Structural Equation Modeling \\
\hline SFT & Sustainable Freight Transportation \\
\hline SO & Social Dimension \\
\hline SPI & Sustainability Performance Index \\
\hline TFN & Triangular Fuzzy Number \\
\hline TISM & Total Interpretive Structure Modeling \\
\hline UFT & Urban Freight Transportation \\
\hline
\end{tabular}

